\title{
The Effect of Temperature on Dynamic Characteristics of Frozen Clay under Principal Stress Rotation
}

\author{
Bin-Long Zhang $\mathbb{D}^{1,},{ }^{1,2}$ Da-Yan Wang $\mathbb{D}^{1},{ }^{1}$ Zhi-Wei Zhou $\left(\mathbb{D},{ }^{1}\right.$ Wei Ma $\mathbb{D}^{1},{ }^{1}$ and Le-Le Lei ${ }^{3}$ \\ ${ }^{1}$ Northwest Institute of Eco-Environment and Resource, State Key Laboratory of Frozen Soil Engineering, \\ Chinese Academy of Science, Lanzhou 730000, China \\ ${ }^{2}$ University of Chinese Academy of Science, Beijing 100049, China \\ ${ }^{3}$ School of Civil and Architectural Engineering, East China University of Technology, Nanchang 330013, China \\ Correspondence should be addressed to Da-Yan Wang; dayanwang2000@163.com
}

Received 10 August 2021; Revised 6 October 2021; Accepted 23 November 2021; Published 20 December 2021

Academic Editor: Hossein Moayedi

Copyright (c) 2021 Bin-Long Zhang et al. This is an open access article distributed under the Creative Commons Attribution License, which permits unrestricted use, distribution, and reproduction in any medium, provided the original work is properly cited.

\begin{abstract}
The foundation soil is always subjected to complex stress, including continuous rotation of the principal stress caused by traffic and earthquake loads. To comprehend the dynamic characteristics of frozen clay under complex stress sate, including continuous rotation of the principal stress, this study investigates the effect of temperature on the dynamic characteristics of frozen clay under principal stress rotation using a frozen hollow cylinder apparatus (FHCA-300). The test results reveal that the cumulative plastic strain of frozen clay samples exponentially increases with the rising of temperature under principal stress rotation. The influence of temperature is more profound with a high cyclic stress ratio (CSR). A decrease in temperature can improve the stiffness of the frozen clay, reduces its energy dissipation, and enhances its ability to resist dynamic loading. However, the principal stress rotation phenomenon may aggravate the damage of frozen clay and increase the energy dissipation and reduces its ability to resist dynamic loading. Based on the experimental data, an empirical expression was proposed to describe the coupling influence of CSRs and temperature on the axial resilient modulus of frozen clay, which can predict the development of axial resilient modulus under different thermal-mechanical conditions.
\end{abstract}

\section{Introduction}

Frozen soils are compound materials composed of solid mineral particles, polycrystalline ice, unfrozen water, and gaseous inclusions. They are widely distributed in cold regions or artificial ground freezing projects $[1,2]$. With the rapid development of the society, projects increasingly have been built on frozen soil in the cold region. Furthermore, the artificial ground freezing (AGF) method, which is widely used in large-scale cross-sea and river-crossing projects in coastal areas, is an effective underground engineering support technology [3]. In these projects, frozen soils as a foundation or supporting wall are subjected to dynamic loads such as those from waves, traffic, and earthquakes. Such dynamic loads may impact the stability of projects, reducing their service lifetime and increasing maintenance costs [4]. Therefore, it is crucial to study dynamic characteristics of frozen soil for engineering design in cold regions and artificial ground freezing projects.

In the past few decades, much attention had been paid to investigate the dynamic properties of frozen soils through triaxial dynamic loading, and many meaningful results were obtained. For example, the effects of temperature, confining pressure, freeze-thaw cycles, initial compaction degree, and initial water content on the dynamic shear modulus and damping ratio of various frozen soils were also investigated under multistage cyclic loading by using a triaxial apparatus [5-8]. The corresponding empirical models of maximum dynamic shear modulus were proposed. Furthermore, experimental studies on the residual deformation and stiffness of frozen soils have been conducted under long-term cyclic loadings to investigate the effect of variables, such as soil 
type, cyclic amplitude, frequency, water content, temperature, initial deviatoric stress ratio, and confining pressure [9-19]. The results obtained from tests showed that the residual deformation increases significantly with the increase of cycles, cyclic stress ratio, temperature, freeze-thaw cycles, and cyclic amplitude but decreases with that of frequency, water content, and confining pressure. Additionally, some results reported that the stiffness decreases at the initial stage and then tends to stabilize, whereas some other results suggested that the stiffness increases as the number of cycles increases. All the previously mentioned research plays a great role in understanding the dynamic properties of frozen soils. However, on the one hand, consensus regarding stiffness change has not been reached. On the other hand, most research efforts were dedicated to cyclic triaxial loadings without the rotation of principal stress, and limited attention was paid to the characterization of dynamic behavior with rotation of principal stress axes.

In actual engineering, the stress path of soil foundation is complex, and the amplitude of principal stress acting on the geotechnical structures constantly changes under dynamic loadings; meanwhile, principal stress axes constantly rotate [20-22]. However, it is difficult to investigate the characteristics of soil under principal stress rotation due to the intrinsic disadvantages of triaxial apparatuses. Hence, the hollow cylinder apparatuses (HCA) have been developed to explore the characteristics of soil under principal stress rotation and complex stress paths [23-32]. Nakata et al. [23] and Tong et al. [24] reported that an increase in pore pressure and strain could be solely triggered by continuous rotation of the principal stress axis, although the magnitude of the principal stresses remains constant. Erken and Ulker [25] and Huang et al. [26] found that the rotation of the principal stress axis can reduce dynamic strength. Mamou et al. [27] and Wang et al. [28] demonstrated that the principal stress rotation reduces the resilient modulus of the soil without changes in the magnitude of the principal stresses. Besides, Cai et al. [29] and Qian et al. [30] indicated that cyclic principal stress rotation accelerates the accumulative permanent deformation. Wang et al. [31] and Sun et al. [32] obtained similar results. Although these lines of evidence confirm that the principal stress rotation significantly influences the mechanical behaviors of soil, the investigations on the influence of principal stress rotation on the cyclic response of frozen soil remain scarce.

This paper aims to expand the current understanding of frozen soil behavior by investigating the effect of temperature on the dynamic characteristics of frozen clay under the principal stress rotation. A series of dynamic loading tests were conducted using FHCA-300 to assess the evolution of the dynamic strain, stress-strain hysteresis curve, resilient modulus, and damping ratio with number of cycles under principal stress rotation. The results provide a significant guidance for the design and operation of frozen soil engineering.

\section{Test Material and Methods}

2.1. Test Device, Material, and Specimen Preparation. The frozen hollow cylinder apparatus, as shown in Figure 1, was jointly developed by the State Key Laboratory of Frozen Soil
Engineering and GCTS firms. It was employed to perform the cyclic loading tests on frozen soil specimens. Compared with the triaxial apparatus, it was the main instrument for studying the mechanical properties of frozen soil under complex stress paths involving the principal stress rotation that can exert axial force, torque, and internal and outer confining pressure on the installed specimen at a stable negative temperature. The maximum loading frequency of the instrument is $20 \mathrm{~Hz}$; the temperature of the pressure chamber ranges from $-40^{\circ} \mathrm{C}$ to $80^{\circ} \mathrm{C}$ with a precision of $\pm 0.1^{\circ} \mathrm{C}$; the axial stress loading varies from -100 to $100 \mathrm{kN}$; the torque loading range is $-1000-1000 \mathrm{Nm}$; the maximum confining pressure is $22 \mathrm{MPa}$; the confining pressure oil used is dimethyl silicone with viscosity of 50 CS. Additionally, parallel tests under different conditions have been carried out to prove the reliability of the test and the repeatability of this apparatus. As detailed description of this instrument and parameters were provided by Guo et al. [33] and Lei et al. [34], correspondingly, according to the stress of the thin-walled element of the hollow cylindrical specimen, the conversion relationship between the loading parameters of the test apparatus and the stress of the specimen is expressed in Table 1 [35].

We have that $W$ represents the axial load; $M_{\bar{T}}$ represents the torque; $p_{0}$ represents the outer confining pressure; $p_{i}$ represents the inner confining pressure; $r_{0}$ represents the outer radius; $r_{i}$ represents the inner radius; $z, u_{0}$, and $u_{i}$ represent the height, outer diameter, and inner diameter strain, respectively, while $\theta$ is the torsional angle.

The test soil was taken from the cold region of QinghaiTibet Plateau, China, where the Qinghai-Tibet Railway, Laluo Dam, and other projects have been built. The liquid and plasticity limits of the tested soil are $27.7 \%$ and $17.6 \%$, respectively. Based on the Unified Soil Classification System (ASTM, 2011), the tested soil can be classified as the low liquid limit clay (LC). The maximum dry density is $1.77 \mathrm{~g} / \mathrm{cm}^{3}$, and the saturated moisture content is $19.8 \%$. The particle gradation of the soil is shown in Figure 2.

In this study, a standard routine preparation procedure of specimens was adopted to guarantee the uniformity of the specimens. First, the air-dried and crushed soil was sieved by a $2 \mathrm{~mm}$ screen. The soil with a moisture content of $19.8 \%$ was added and mixed uniformly by hands, after which the wet soil was stored in a sealed bag for 24 hours for the even distribution of water. Then, a certain amount of clay was put layer-by-layer into a self-made sample mold with the same thickness (5 layers) and compacted at a certain speed using a sample-making machine. Finally, a hollow cylindrical sample with a height of $200 \mathrm{~mm}$, an outer diameter of $100 \mathrm{~mm}$, and an inner diameter of $60 \mathrm{~mm}$ was obtained with a dry density of $1.77 \mathrm{~g} / \mathrm{cm}^{3}$ (Figure $3(\mathrm{a})$ ). The prepared hollow cylindrical specimen was placed into the pressure chamber of the FHCA-300 apparatus and was quickly frozen at the temperature of $-30^{\circ} \mathrm{C}$ to prevent frost heave and moisture migration. Then, the temperature was set at the desired temperature for 10 hours to ensure the even distribution of the sample temperature (Figure 3(b)). At last, a hollow cylindrical sample of frozen soil was obtained. 


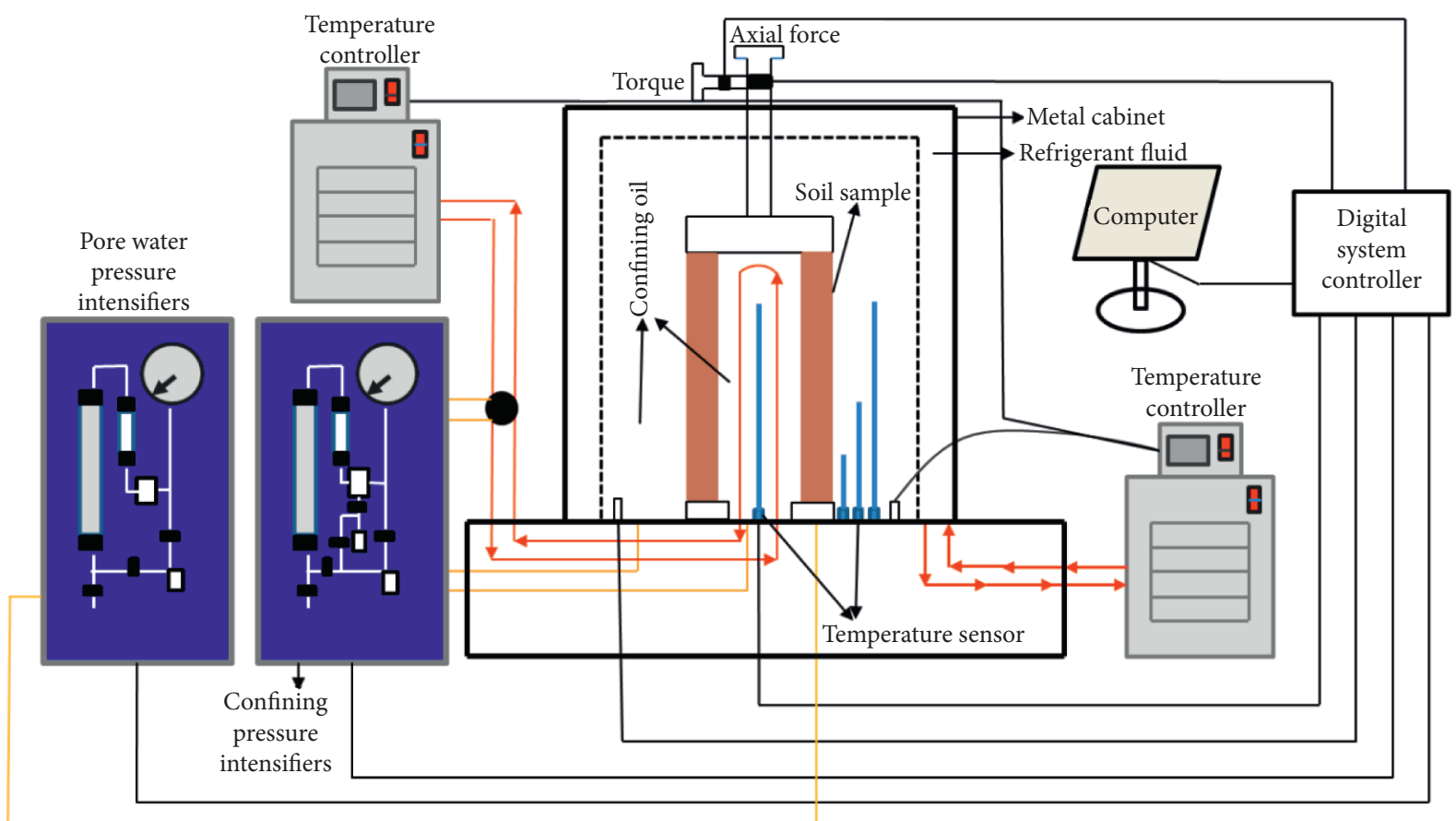

FIgURE 1: Schematic diagram of the structure of frozen hollow cylinder apparatus.

TABLE 1: Equations of relation between test load parameters and stress components.

\begin{tabular}{lcc}
\hline & Stress & Strain \\
\hline Vertical & $\sigma_{z}=W / \pi\left(r_{0}^{2}-r_{i}^{2}\right)+p_{0} r_{0}^{2}-p_{i} r_{i}^{2} / r_{0}^{2}-r_{i}^{2}$ & $\varepsilon_{z}=\Delta h / H_{0}$ \\
Radial & $\sigma_{r}=p_{0} r_{0}+p_{i} r_{i} / r_{0}+r_{i}$ & $\varepsilon_{r}=-\left(u_{0}-u_{i} / r_{0}-r_{i}\right)$ \\
Circumferential & $\sigma_{\theta}=p_{0} r_{0}-p_{i} r_{i} / r_{0}-r_{i}$ & $\varepsilon_{\theta}=-\left(u_{0}+u_{i} / r_{0}+r_{i}\right)$ \\
Shear & $\tau_{z \theta}=M_{T}\left(r_{0}+r_{i}\right) / \pi\left(r_{0}^{4}-r_{i}^{4}\right)$ & $\gamma_{z \theta}=\gamma_{\theta z}=2 \Delta \theta\left(r_{0}^{3}-r_{i}^{3}\right) / 3 H_{0}\left(r_{0}^{2}-r_{i}^{2}\right)$ \\
\hline
\end{tabular}

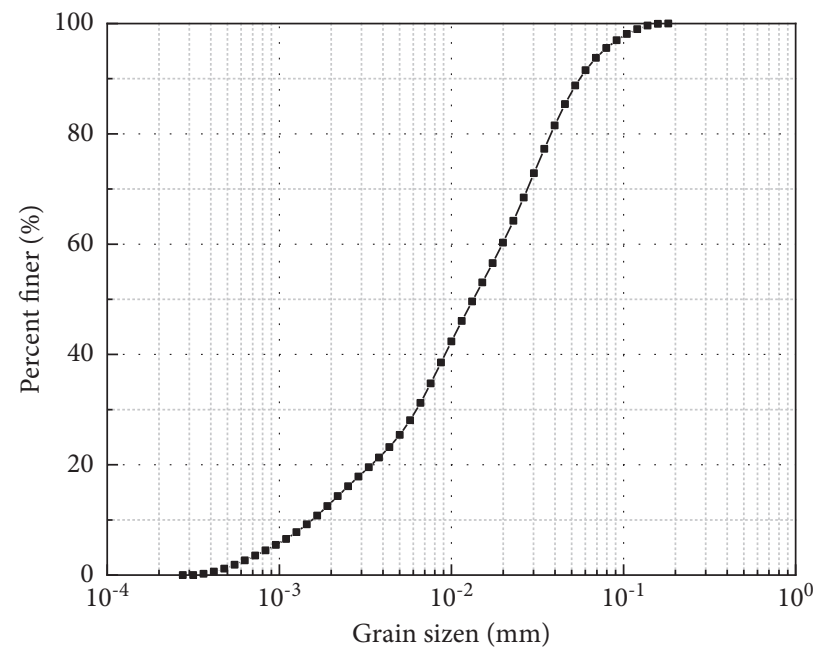

FIGURE 2: Cumulative curve of grain size grading of the frozen clay.

2.2. Test Program. Ishihara and Towhata [35] proved that it is possible to use a hollow cylinder apparatus to achieve circular stress paths in the $\tau \sim\left(\sigma_{z}-\sigma_{\theta}\right) / 2$ plane through coupled dynamic loading of axial force and torque under principal stress rotation. Under principal stress rotation, the stress is composed of deviator stress and shear stress. To simultaneously reflect the influence of deviator stress and shear stress on the test, the CSR was defined [36-38]: 


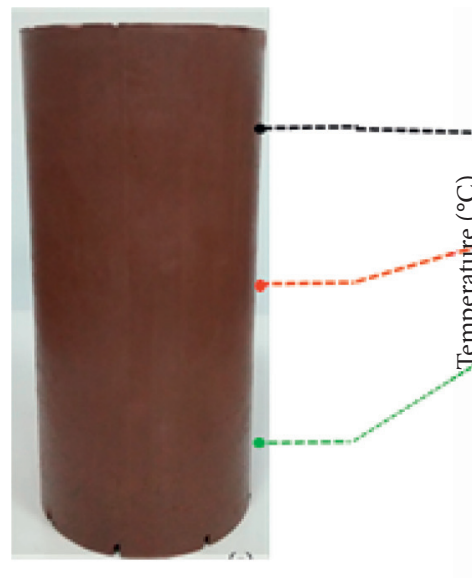

(a)

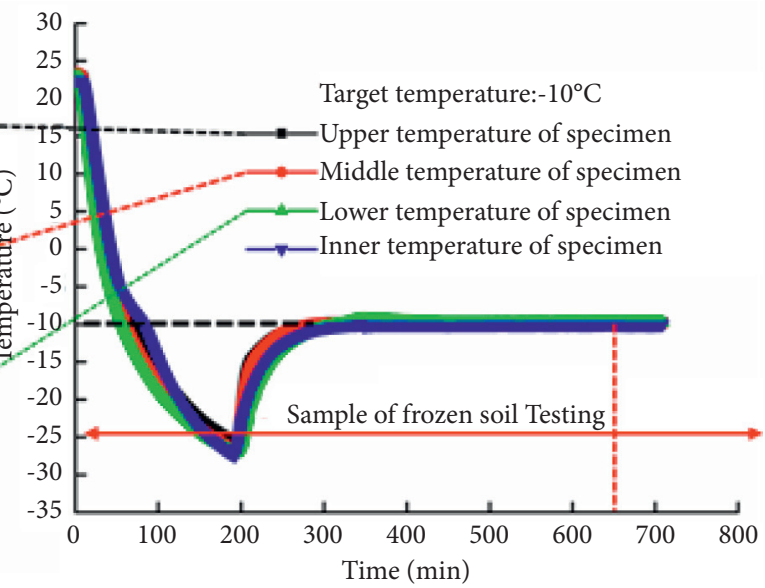

(b)

FiguRE 3: Formation process of frozen soil samples: (a) hollow cylindrical specimen; (b) the temperature change process of hollow cylindrical sample.

$$
\operatorname{CSR}=\frac{q_{\mathrm{cyc}}}{2 \sigma_{c}}
$$

where $q_{c y c}$ is the maximum shear stress peak value and $\sigma_{c}$ is the confining pressure; $q_{\text {cyc }}=\sqrt{\tau^{2}+\left(\left(\sigma_{z}-\sigma_{\theta}\right) / 2\right)^{2}}$, where $\tau$ is the shear stress, $\sigma_{z}$ is the axial stress, and $\sigma_{\theta}$ is the tangential stress.

This test aims to investigate the influence of temperature on the dynamic characteristics of frozen clay with the rotation of the principal stress axis under different CSRs. The frequency was selected as $0.2 \mathrm{~Hz}$ during the cyclic loading test. This is because the frequency between 0.05 and $1 \mathrm{~Hz}$ has little effect on its dynamic characteristics [26]. Additionally, the internal pressure and external pressure were set at $2.5 \mathrm{MPa}$, and the test temperatures of $-8,-10,-13$, and $-15^{\circ} \mathrm{C}$ were selected to study the dynamic characteristics of frozen soil undergoing the cryogenic process. Previous studies [16, 39] provided a reference to determine the amplitudes of cyclic shear stress which were chosen as 1.125 MPa, 1.5 MPa, 1.875 MPa, and $2.25 \mathrm{MPa}$ corresponding to the CSRs of $0.225,0.300,0.375$, and 0.45 in the experiments. The details of the testing plans are shown in Table 2. The initial static deviating stress and confining pressure were applied on the specimens to reach a stable stress condition for the dynamic test. Then, cyclic loading of axial stress and torque was carried out on frozen samples, where the representative loading waveforms and stress path are shown in Figure 4. During the test, a total of 50 points' data were recorded for each loading cycle. The specimens were loaded to 250 cycles, or the axial strain reached the failure limit of $20 \%$. The operating procedures of hollow cylinder torsional shear tests are shown in Figure 5.

\subsection{Determination of Resilient Modulus and Damping Ratio.} During the test, a hysteresis loop can be obtained under cyclic loadings, as shown in Figure 6, from which the resilient modulus and the damping ratio can be derived. The secant modulus determined from the hysteresis loop is considered as the resilient modulus that can be calculated as follows:

$$
E_{\text {resilient }}\left(G_{\text {resilient }}\right)=\frac{\sigma_{\max }\left(\tau_{\max }\right)-\sigma_{\min }\left(\tau_{\min }\right)}{\varepsilon_{\max }\left(\gamma_{\max }\right)-\varepsilon_{\min }\left(\gamma_{\min }\right)},
$$

where $\sigma_{\max }$ is the maximum axial stress, $\sigma_{\min }$ is the minimum axial stress, $\varepsilon_{\max }$ is the maximum axial strain, and $\varepsilon_{\min }$ is the minimum axial strain.

The damping ratio is an important parameter to reflect the energy consumption of frozen clays under cyclic loadings; its formulation for frozen soil can be expressed as follows:

$$
\lambda=\frac{1}{4 \pi} \frac{A_{L}}{A_{T}},
$$

where $A_{L}$ is the area of the hysteresis loop and $A_{T}$ is the area of the triangle.

\section{Test Result and Discussion}

3.1. Cumulative Plastic Strain. Figure 7 presents the evolution of the cumulative plastic strain versus the number of cycles under the different conditions of temperature and CSR. When CSR $=0.225$, the cumulative plastic strain increases slightly with the increase of the number of cycles at low temperatures $\left(-15^{\circ} \mathrm{C}\right.$ and $-13^{\circ} \mathrm{C}$, as shown in Figure $7(\mathrm{a})$ ), while the cumulative plastic strain increases rapidly as the number of cycles increases at the higher temperatures at $-10^{\circ} \mathrm{C}$ and $-8^{\circ} \mathrm{C}$. Clearly, the cumulative plastic strain increases significantly as the temperature increases from $T=-15^{\circ} \mathrm{C}$ to $T=-8^{\circ} \mathrm{C}$ at the same number of cycles. For the cases of $\mathrm{CSR}=0.300,0.375$, and 0.450 presented in Figures 7(b)-7(d), it is clear that the evolution of the cumulative plastic strain is similar to that of CSR $=0.225$, but the value and rate of the cumulative plastic strain increase with the increasing of CSR. To further exhibit the effect of temperature on the cumulative plastic strain, the relationship between the final cumulative plastic strain 
TABLE 2: Conditions of tests on frozen clay.

\begin{tabular}{lccr}
\hline Inner and outer confining pressure $/ \mathrm{MPa}$ & Frequency/Hz & Cyclic stress ratio (CSR) & Temperature $/{ }^{\circ} \mathrm{C}$ \\
\hline & & 0.225 & 0.300 \\
2.5 & 0.2 & 0.375 & $-8-10-13-15$ \\
& & 0.450 & \\
\hline
\end{tabular}

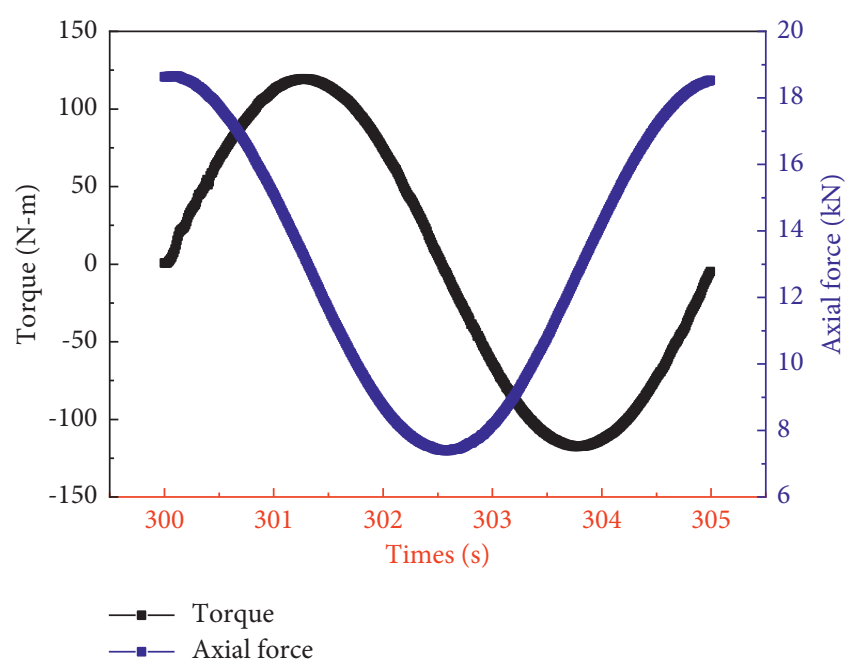

(a)

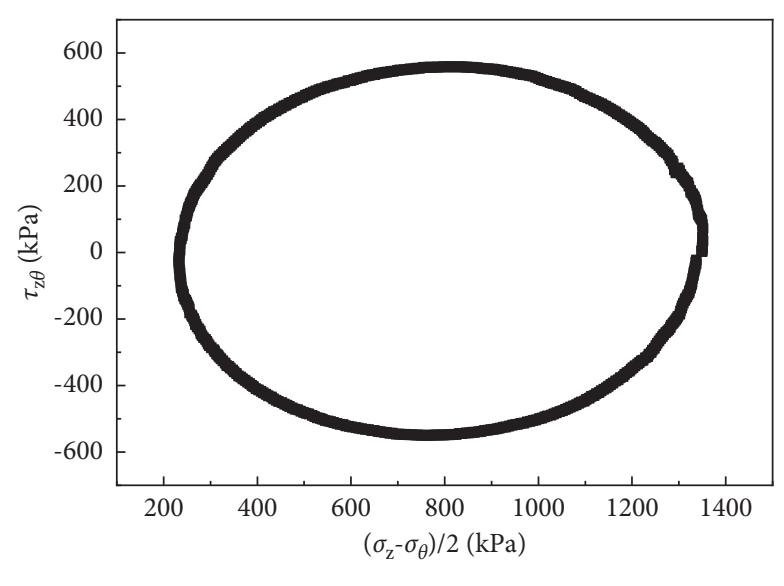

- - Circular stress path

FIGURE 4: Representative loading waveforms and typical record of stress path. (a) Representative loading waveforms. (b) Typical record of stress path.

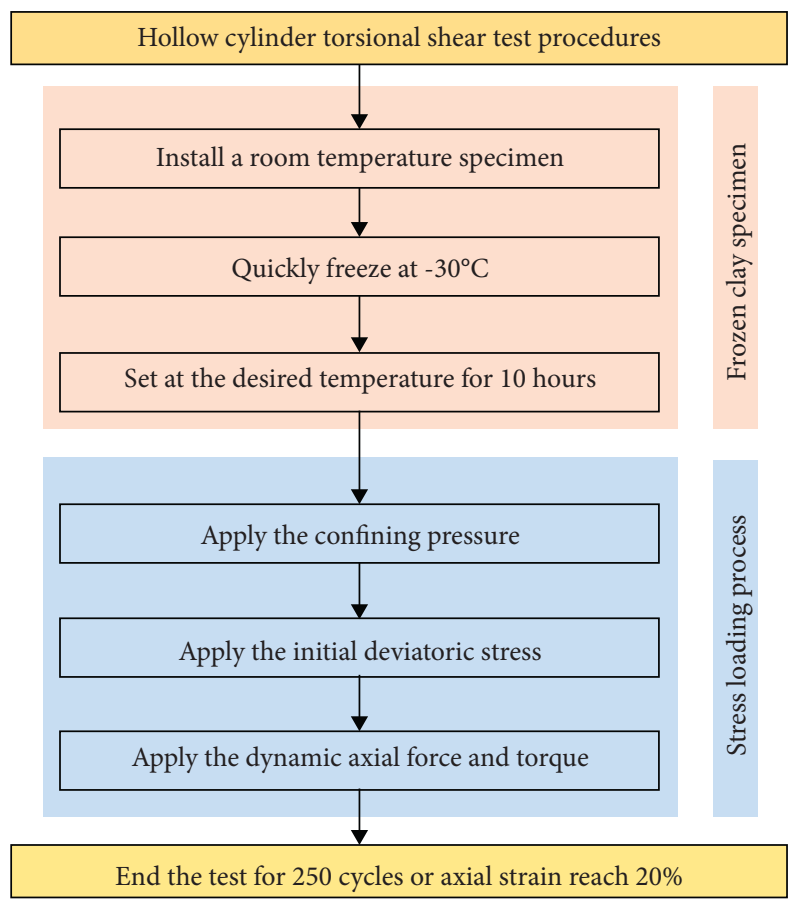

FIGURE 5: The operating procedures of hollow cylinder torsional shear tests. 


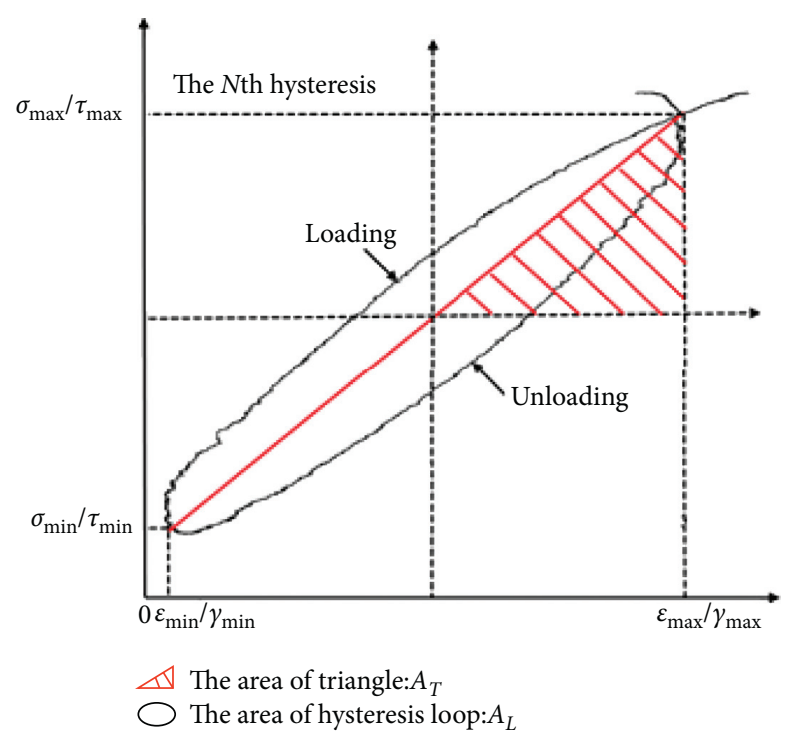

FIgURE 6: The determination method of the resilient modulus and damping ratio of frozen clay.
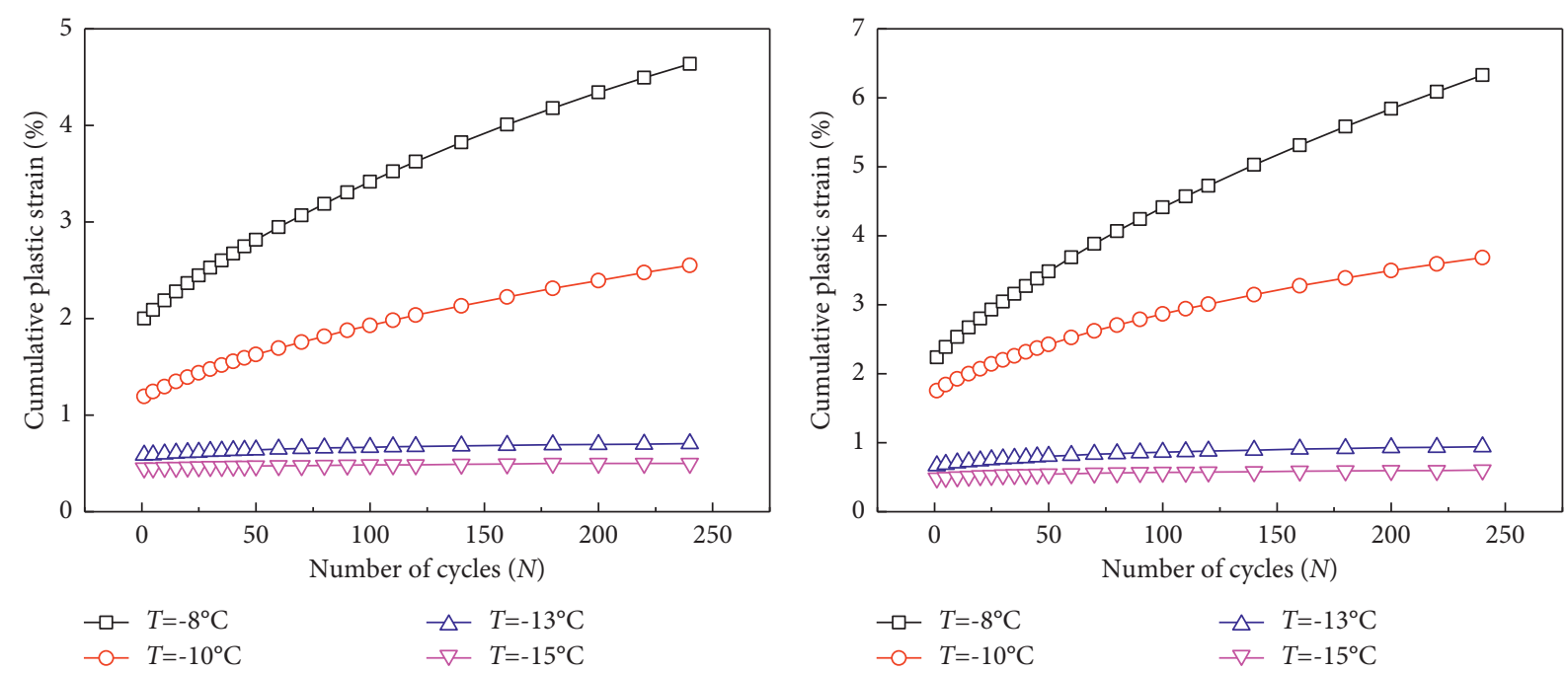

$$
\begin{aligned}
& \multimap-T=-8^{\circ} \mathrm{C} \\
& \multimap-T=-10^{\circ} \mathrm{C}
\end{aligned}
$$

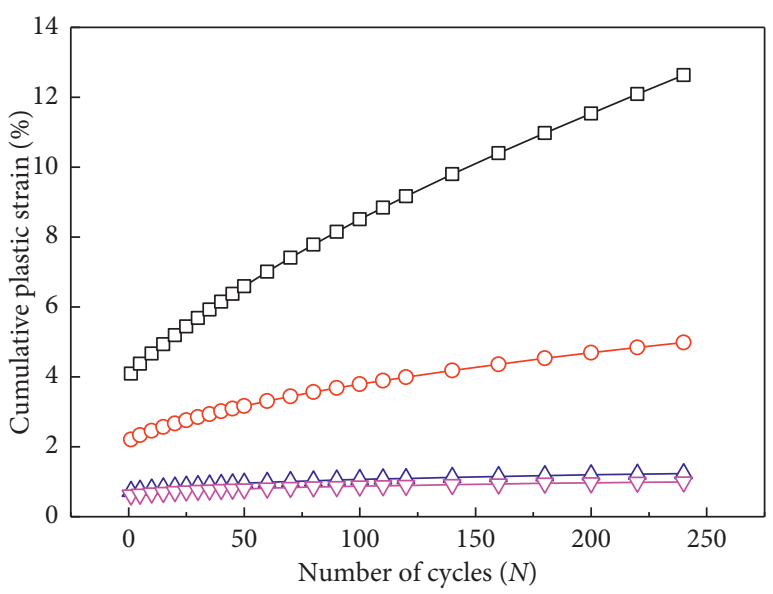

$\rightarrow-T=-8^{\circ} \mathrm{C}$

$-\mathrm{O}-\mathrm{T}=-10^{\circ} \mathrm{C}$

$$
\triangle-T=-13^{\circ} \mathrm{C}
$$$$
-\nabla-T=-15^{\circ} \mathrm{C}
$$

(c) (b)

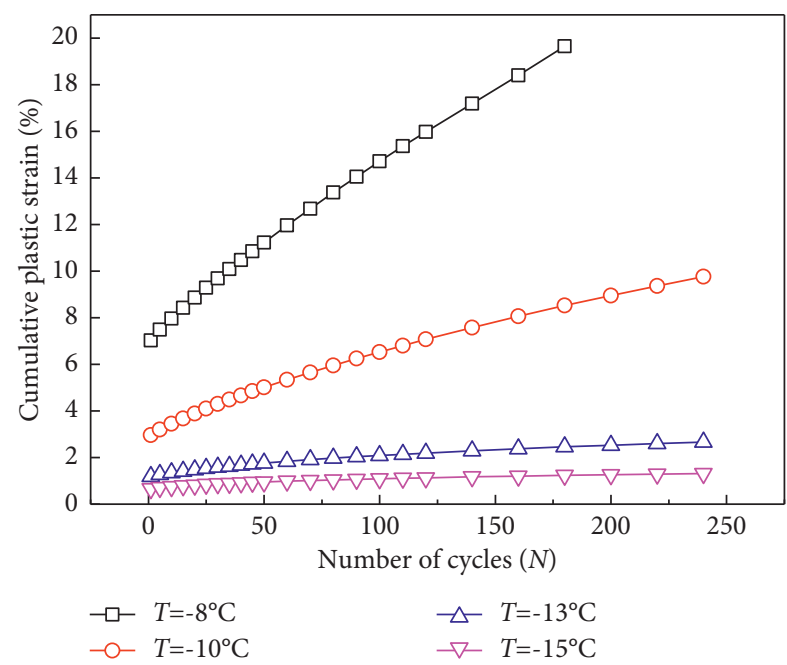

(d)

FIGURE 7: The evolution of the cumulative plastic strain versus the number of cycles at four temperatures and CSRs. (a) CSR $=0.225$. (b) CSR $=0.300$. (c) $\operatorname{CSR}=0.375$. (d) $\operatorname{CSR}=0.450$. 
$\left(\varepsilon_{N=240}\right)$ and temperature under four CSRs is plotted in Figure 8. In general, the final cumulative plastic strain exponentially increases with the increase of the temperature at a certain CSR. The greater CSR means a more significant growth rate. The results imply that the cyclic deformation behaviors of frozen soil are sensitive to temperature changes. There is static friction between solid particles and the cementing force between ice and soil in frozen soil [40-42]. The mechanism of frozen soils is different from that of unfrozen soil. The cementing force between ice and soil in frozen soil decreases with the increase of the temperature, decreasing the strength of the frozen specimens [43]. Therefore, the cumulative plastic strain increases sharply with the rising temperature at a given CSR. The effect of temperature seems to be more profound on cumulative plastic strain at a high CSR.

3.2. Axial Resilient Modulus and Damping Ratio. Figure 9 depicts the evolution of representative axial stress strain versus the number of cycles at four temperatures as $\mathrm{CSR}=0.375$. As shown in Figure 9(a), the area of the hysteresis loop is large in the initial cycles, and, with the increase of number of cycles, the cumulative plastic strain and the area of the hysteresis loop decrease. In contrast, the slope of the hysteresis loop is small in the initial cycles, and, with the increase of the number of cycles, the slope of the hysteresis loop increases. The results show that as the number of cycles increases, the stiffness of frozen samples will be enhanced, while the recoverable strain and the amount of dissipated energy decrease with the increase of the number of cycles at high temperatures. Comparing Figures 9(a)-9(d) reveals that, at a lower temperature, the shape of the hysteresis loop changes slightly with the increase of the number of cycles. To further highlight the effect of temperatures on axial stress strain, the typical axial stress-strain hysteresis hoops at a different temperature under $N=50$ and 200 are plotted in Figure 10. Clearly, when the temperature decreases, the plastic strain and the area of the hysteresis loop decrease sharply at the initial stage and then decrease slowly, while the slope of the hysteresis loop increases (see Figure 10). These results imply that the stiffness of frozen soil samples is enhanced with the decrease in temperature, while amount of energy dissipation decreases.

Resilient modulus is a key parameter for engineering design and performance evaluation. Figure 11 depicts the evolution of the axial resilient modulus versus the number of cycles at different temperatures and CSRs. In Figures 11(a)11(d), when $\mathrm{CSR}=0.225$ and $T=-15^{\circ} \mathrm{C}$, the resilient modulus rapidly decreases at the beginning of the loading stage and then fluctuates around a steady value as the loading cycles increase. For the case of $\mathrm{CSR}=0.225$ and $T=-8^{\circ} \mathrm{C}$, the resilient modulus decreases slightly at the beginning of the loading stage and then increases significantly as the loading cycles increase. Interestingly, the evolution characteristics of axial resilient modulus in this paper differ from those obtained in the cyclic triaxial test of frozen soil [16-19]. In this study, the axial resilient modulus decreases at the initial loading stage and then increases. That is because the inherent anisotropic structure in frozen soil is more significant, and the particles tend to rotate to support the rotation of principal stress during the first few cycles. Then, the frozen samples achieve stable structure after continuous orientation, realignment, and rearrangement [44-46]. Furthermore, Figures 11(a)-11(d) show that as the temperature increases from -15 to $-8^{\circ} \mathrm{C}$, the axial resilient modulus decreases significantly at a given number of cycles. Thus, the temperature has a significant impact on the variation of resilient modulus. The strength increases with the decrease of the temperature. Therefore, its stiffness and resilient modulus increase. However, the results from Ling et al. [14] show that the decrease of temperature has little influence on the stiffness of frozen soil between $0^{\circ} \mathrm{C}$ and $-1.5^{\circ} \mathrm{C}$. That may imply that the stiffness of frozen soil can be improved only when the temperature is lower than the freezing point.

To better analyze the influence of temperature and CSR energy dissipation, Figure 12 illustrates the evolution of the axial damping ratio versus the number of cycles at different temperatures and CSRs. For the case of CSR $=0.225$ and CSR $=0.300$, as shown in Figures 12(a) and 12(b), on the whole, the damping ratio of specimens reduces gradually at the initial stage and subsequently reaches a relatively steady value. For the case of CSR $=0.375$ and $C S R=0.450$, as shown in Figures $12(\mathrm{c})$ and $12(\mathrm{~d})$, when $T=-15^{\circ} \mathrm{C}$ and $-13^{\circ} \mathrm{C}$, the damping ratio of specimens also decreases rapidly at the initial stage and then tends to stabilize as the number of cycles increases. The evolution of the damping ratio indicates that energy dissipation gradually decreases with increase of the number of cycles due to a more stable structure formation at lower temperatures [17]. When $T=-10^{\circ} \mathrm{C}$ and $-8^{\circ} \mathrm{C}$, the damping ratio of specimens decreases at the initial stage and then increases gradually as the number of cycles increases. This is possible because the effect of torsional stress on the structural damage of frozen samples becomes more significant at a higher temperature and CSR, leading to the significant microfracturing phenomenon. Furthermore, it can be seen that the damping ratio of all specimens increases as the temperature rises. That is because the cementing force of ice decreases as the temperature rises. Thus, the strength of the specimens is reduced, and the obvious cumulative plastic strain occurs, increasing the energy dissipation.

\subsection{Torsional Resilient Modulus and Damping Ratio. To} analyze the effect of temperature on the torsional stressstrain relationship, the representative torsional stress-strain responses with the number of cycles at four temperatures as $\mathrm{CSR}=0.375$ are shown in Figure 13. It can be found that hysteresis loops obtained from torsional stress strain move to the left, and the distance between the hysteresis loops decreases as the number of cycles increases. At the end of cyclic loading, the curves of hysteresis loops nearly overlap because the plastic strain gradually tends to stabilize. Moreover, the area of hysteresis loops decreases with increasing the number of cycles, while the hysteresis loops gradually lean toward to the torsional stress axial (vertical 


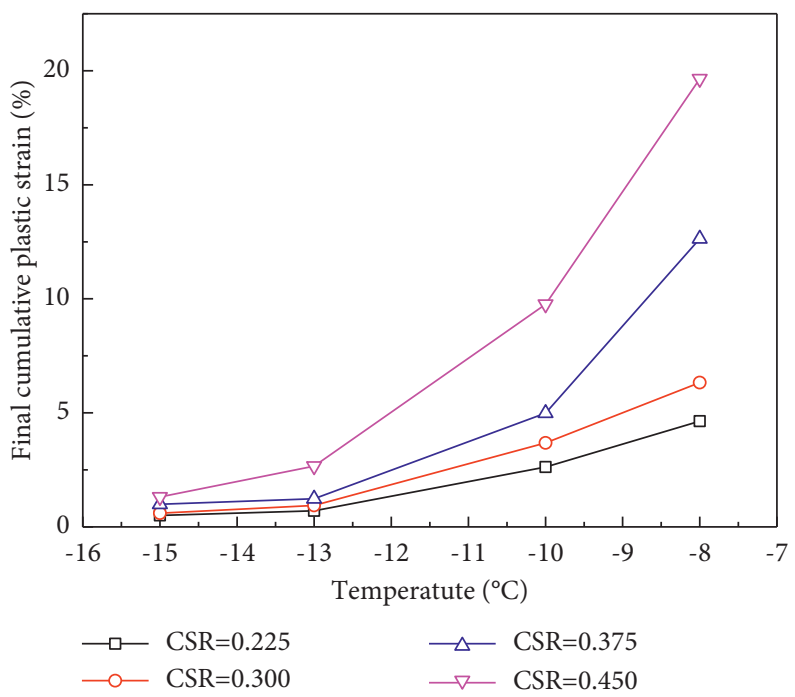

FIgURE 8: Relationship between the final cumulative plastic strain $\left(\varepsilon_{N=240}\right)$ and temperature under four CSRs.

axial) with increase in the number of cycles. Figure 14 illustrates the representative torsional stress-strain responses at a given number of cycles and different temperatures. It can be observed that the hysteresis loops from torsional stressstrain responses move to the right, and the area of hysteresis loops increases as the temperature rises. Furthermore, the hysteresis loops gradually lean toward to the torsional axial strain (horizontal axial) as the temperature rises, which implies that the stiffness of frozen clay decreases with the increasing of the temperature. However, it should be noted that the stiffness and energy dissipation of frozen clay vary slightly as the temperature changes from $-10^{\circ} \mathrm{C}$ to $-8^{\circ} \mathrm{C}$, showing that there may be a critical temperature for a given CSR. That needs further exploration in the future.

The study on torsional resilient modulus of frozen soil has been relatively scarce until now. Figure 15 depicts the evolution of the torsional resilient modulus versus the number of cycles at different temperatures and CSRs. Figures 15(a)-15(d) show that the evolution laws of the torsional resilient modulus can be divided into three types at different temperatures. For the case of $T=-15^{\circ} \mathrm{C}$, the torsional resilient modulus decreases rapidly at the initial cyclic loading stage and then reaches a relatively steady value. In the case of $T=-13^{\circ} \mathrm{C}$ and $T=-10^{\circ} \mathrm{C}$, it decreases slightly at the initial cyclic loading stage and then increases slightly with the increasing of the number of cycles. For the case of $T=-8^{\circ} \mathrm{C}$, it significantly increases with the increasing number of cycles, and its growth rate gradually reduces. Obviously, the evolution characteristics of torsional modulus versus number of cycles mostly depend on the changes in temperature. Furthermore, the results show that the evolution of the torsional shear modulus is similar to that of the axial resilient modulus. However, the value of the torsional shear modulus is smaller than that of the axial resilient modulus. The torsional shear modulus evolution rules of frozen samples are inconsistent with those derived from previous studies of unfrozen soil $[28,44]$. The unfrozen soil specimen is softened by the accumulation of pore water pressure under cyclic loading. In contrast, the frozen soil sample is hardened under cyclic loading because of the cementation of ice $[28,44]$. Besides, the temperature has a significant impact on the torsional resilient modulus. For specimens with low temperatures, the torsional resilient modulus is large. The comparison between axial resilient modulus and torsional resilient modulus (Figures 11 and 15) shows that the axial resilient modulus is about four times the torsional resilient modulus.

Figure 16 depicts the evolution of the torsional damping ratio versus the number of cycles under different temperatures. The torsional damping ratio decreases rapidly at the beginning of the cyclic loading stage. After that, the decrease rate of the torsional damping ratio becomes slower than before, mainly because stress acting on specimens along the axial direction is higher than that along the torsional direction, causing the cyclic densification of samples and increasing torsional strength. Therefore, the torsional damping ratio gradually decreases with the increase of the number of cycles. However, the change of torsional damping ratio for the case of $\mathrm{CSR}=0.375$ and $T=-10^{\circ} \mathrm{C}$ shown in Figure $16(\mathrm{c})$ is different from others, which may be due to the sample inhomogeneity. Additionally, the increase in temperature also promotes the torsional energy dissipation of the sample to increase, with the increasing of the torsional damping ratio. What is more, it could be seen from Figures 12 and 16 that the axial damping ratio is greater than the torsional damping ratio.

\section{Prediction Model of Axial Resilient Modulus}

The resilient properties of soils have been extensively investigated by many researchers, and lots of empirical models were established to predict the resilient modulus under different conditions [42-46]. The most well-known and commonly used resilient modulus predicted models in existing literatures are presented in Table 3. Based on the existing empirical models for resilient modulus, it should be 

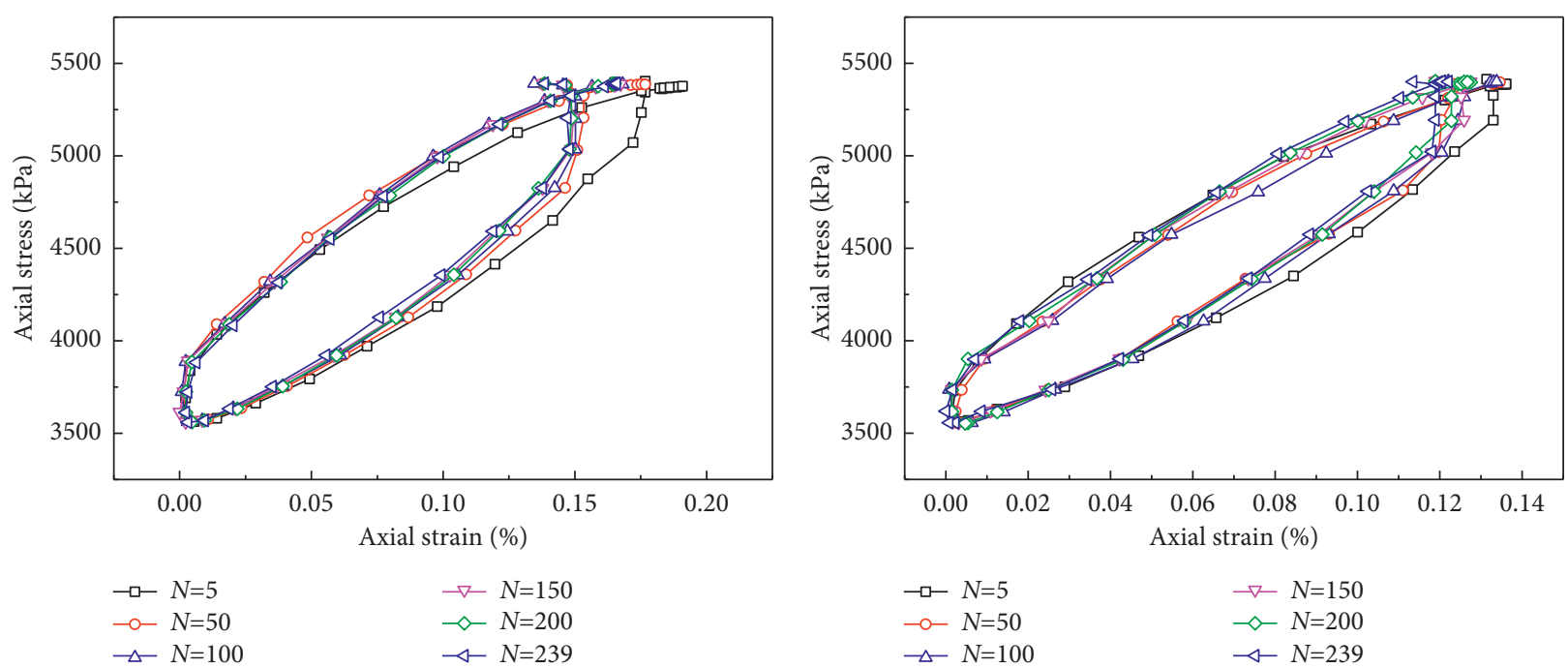

(a)

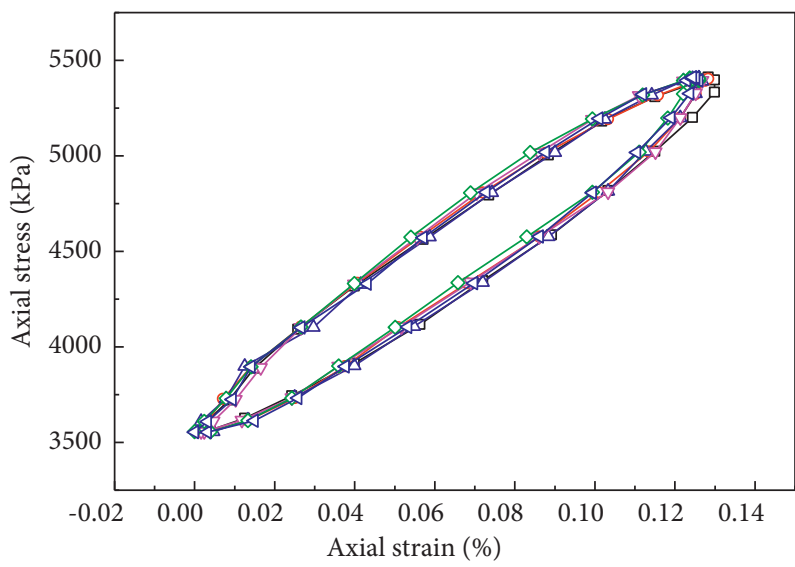

(b)

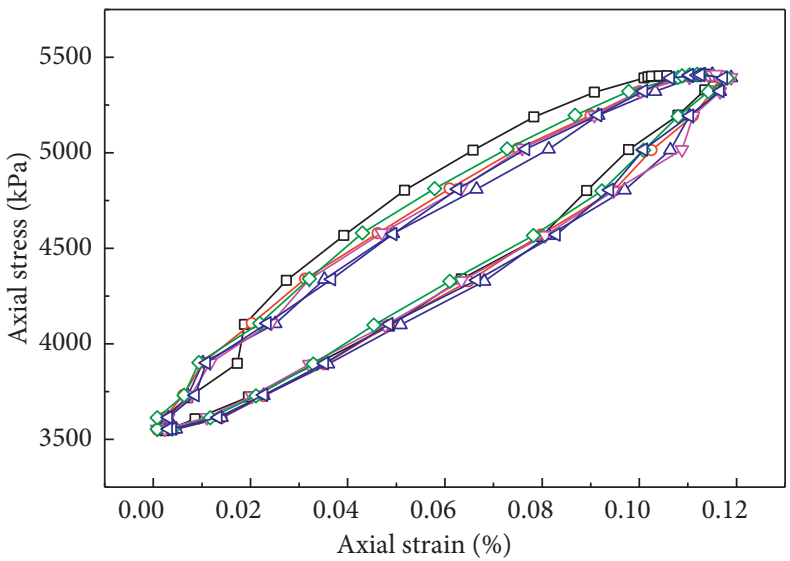

$$
\begin{array}{ll}
\neg-N=5 & \neg-N=150 \\
\neg-N=50 & \checkmark N=200 \\
\neg-N=100 & \checkmark-N=239
\end{array}
$$$$
\rightarrow-N=5
$$$$
\rightarrow-N=150
$$$$
\text { -0 } N=50
$$$$
\diamond N=200
$$

(c)

(d)

FIGURE 9: The evolution of representative axial stress-strain hysteresis loop versus the number of cycles at four temperatures as CSR $=0.375$. (a) $\mathrm{T}=-8^{\circ} \mathrm{C}$. (b) $\mathrm{T}=-10^{\circ} \mathrm{C}$. (c) $\mathrm{T}=-13^{\circ} \mathrm{C}$. (d) $\mathrm{T}=-15^{\circ} \mathrm{C}$

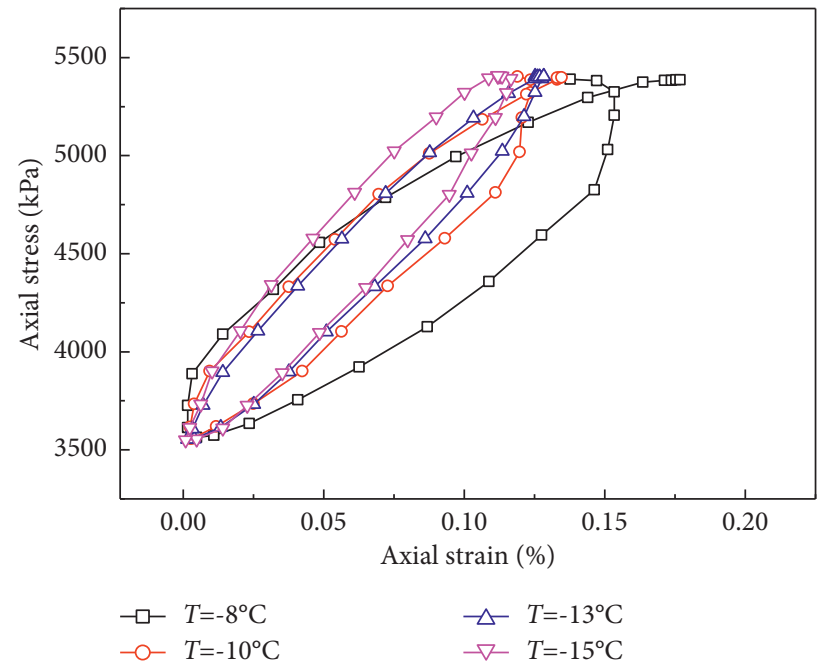

(a)

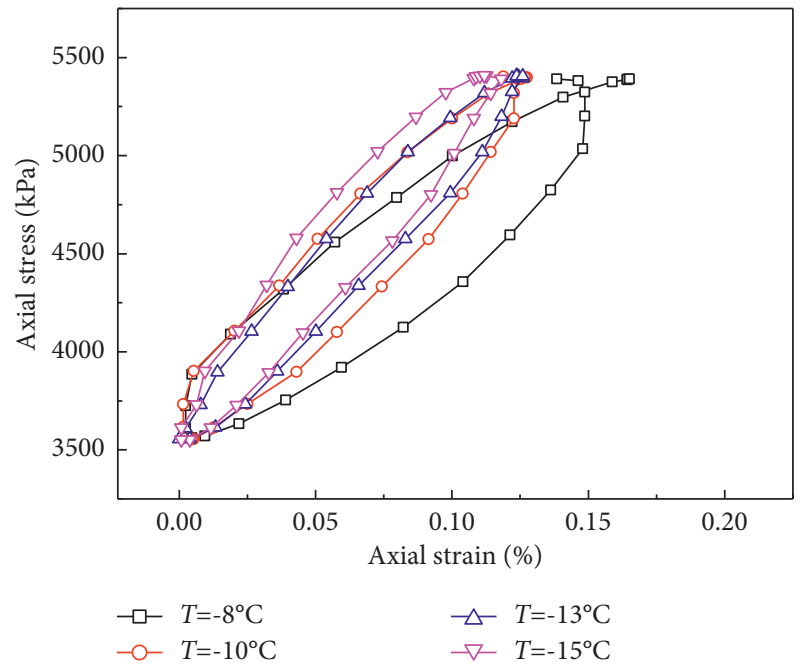

(b)

Figure 10: The representative axial stress-strain hysteresis hoop for a given number of cycles at different temperatures. (a) $N=50$. (b) $N=200$. 

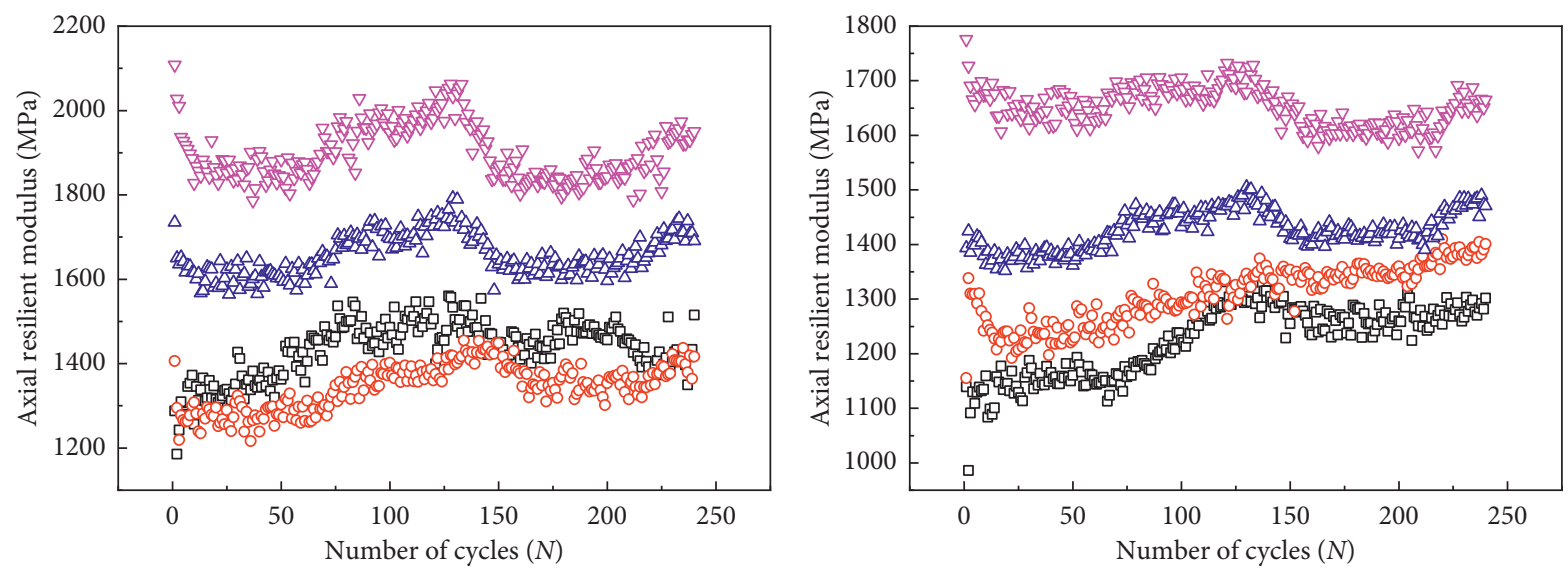
- $T=-8^{\circ} \mathrm{C}$
- $T=-10^{\circ} \mathrm{C}$
$\Delta T=-13^{\circ} \mathrm{C}$
$\nabla \quad \mathrm{T}=-15^{\circ} \mathrm{C}$

ㅁ $T=-8^{\circ} \mathrm{C}$

- $T=-10^{\circ} \mathrm{C}$

$\triangle T=-13^{\circ} \mathrm{C}$

$\nabla \mathrm{T}=-15^{\circ} \mathrm{C}$

(a)
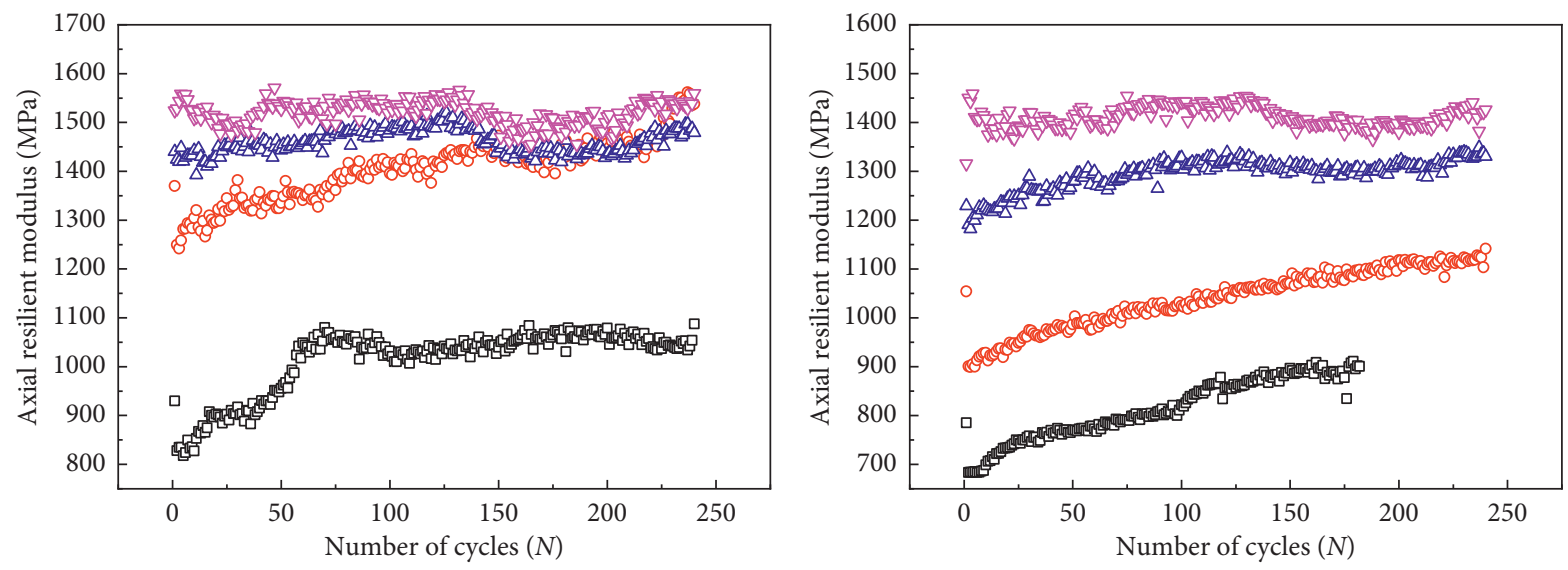
ㅁ $\quad \mathrm{T}=-8^{\circ} \mathrm{C}$
- $T=-10^{\circ} \mathrm{C}$
$\triangle T=-13^{\circ} \mathrm{C}$
$\nabla \quad \mathrm{T}=-15^{\circ} \mathrm{C}$
ㅁ $T=-8^{\circ} \mathrm{C}$
- $T=-10^{\circ} \mathrm{C}$
$\triangle T=-13^{\circ} \mathrm{C}$
$\nabla \quad \mathrm{T}=-15^{\circ} \mathrm{C}$

(c)

(d)

FIGURE 11: The evolution of the axial resilient modulus versus the number of cycles at different temperatures and CSRs. (a) CSR $=0.225$. (b) $\mathrm{CSR}=0.300$. (c) $\operatorname{CSR}=0.375$. (d) $\mathrm{CSR}=0.450$.
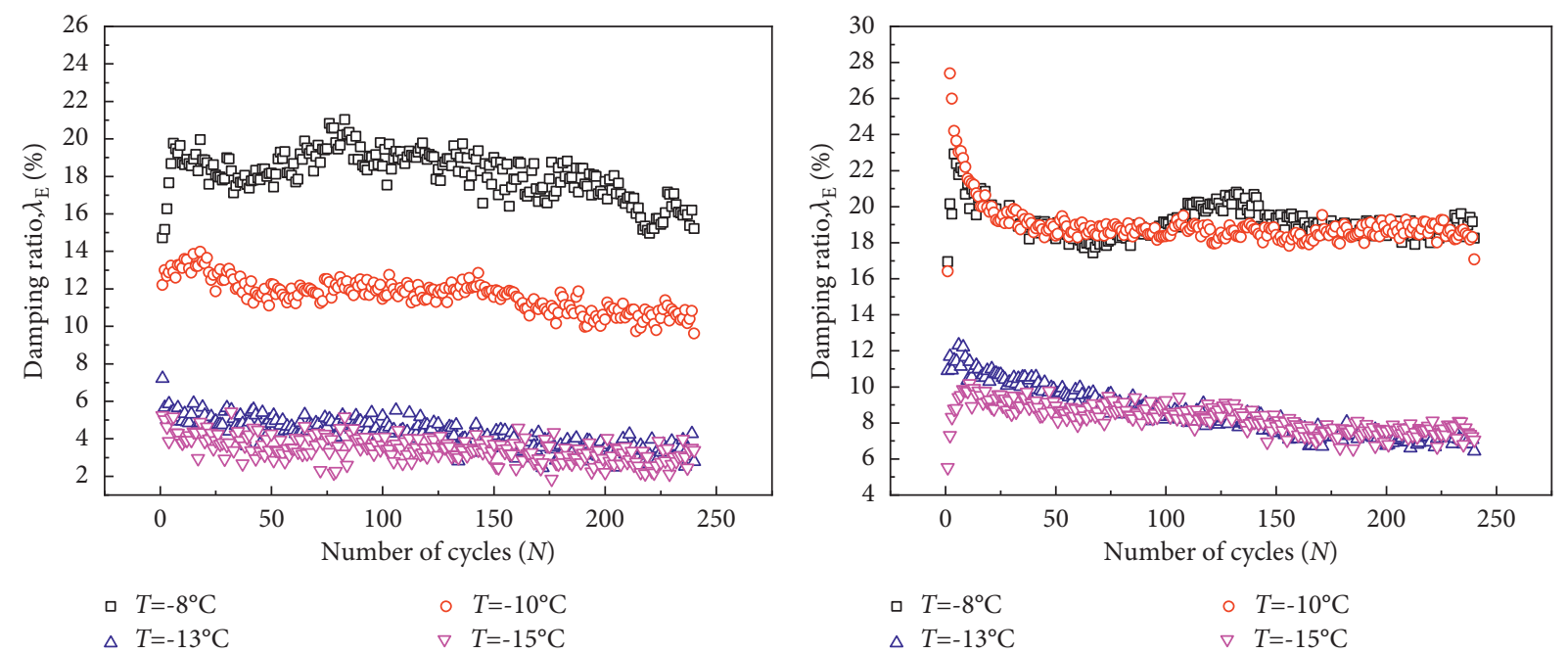
ㅁ $T=-8^{\circ} \mathrm{C}$
- $T=-10^{\circ} \mathrm{C}$

$\triangle T=-13^{\circ} \mathrm{C}$

(b)

FIGURE 12: Continued. 


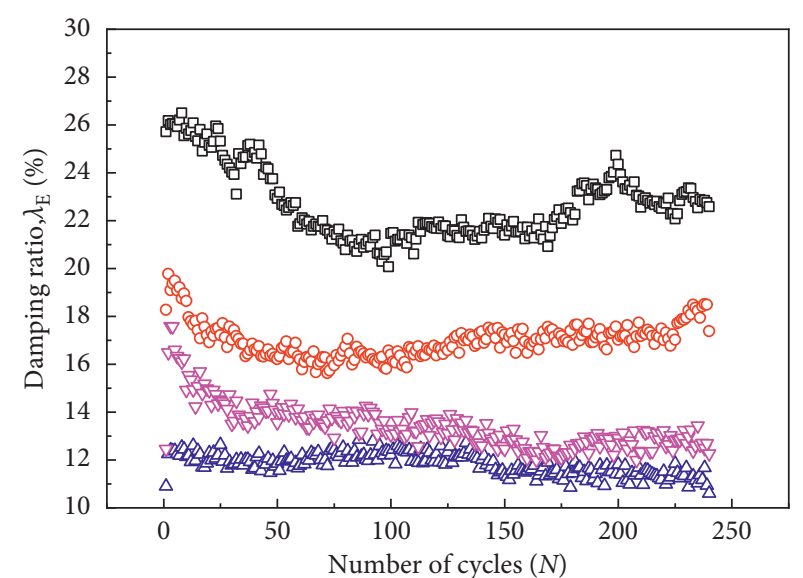

ㅁ $T=-8^{\circ} \mathrm{C}$

$\triangle T=-13^{\circ} \mathrm{C}$
- $T=-10^{\circ} \mathrm{C}$

$\nabla T=-15^{\circ} \mathrm{C}$

(c)

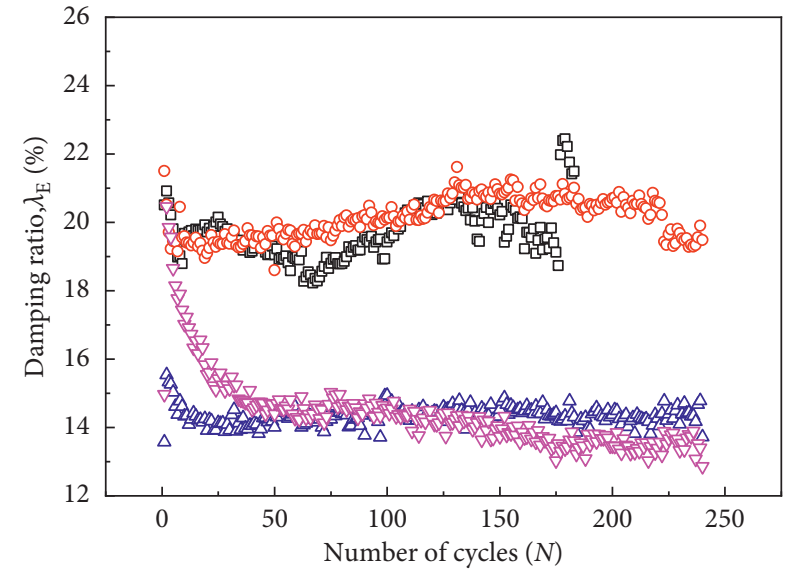

ㅁ $T=-8^{\circ} \mathrm{C} \quad \circ \mathrm{T}=-10^{\circ} \mathrm{C}$

$\triangle T=-13^{\circ} \mathrm{C}$

(d)

FIGURE 12: The evolution of the axial damping ratio versus the number of cycles under different temperatures and CSRs. (a) CSR $=0.225$. (b) $\mathrm{CSR}=0.300$. (c) $\mathrm{CSR}=0.375$. (d) $\mathrm{CSR}=0.375$.
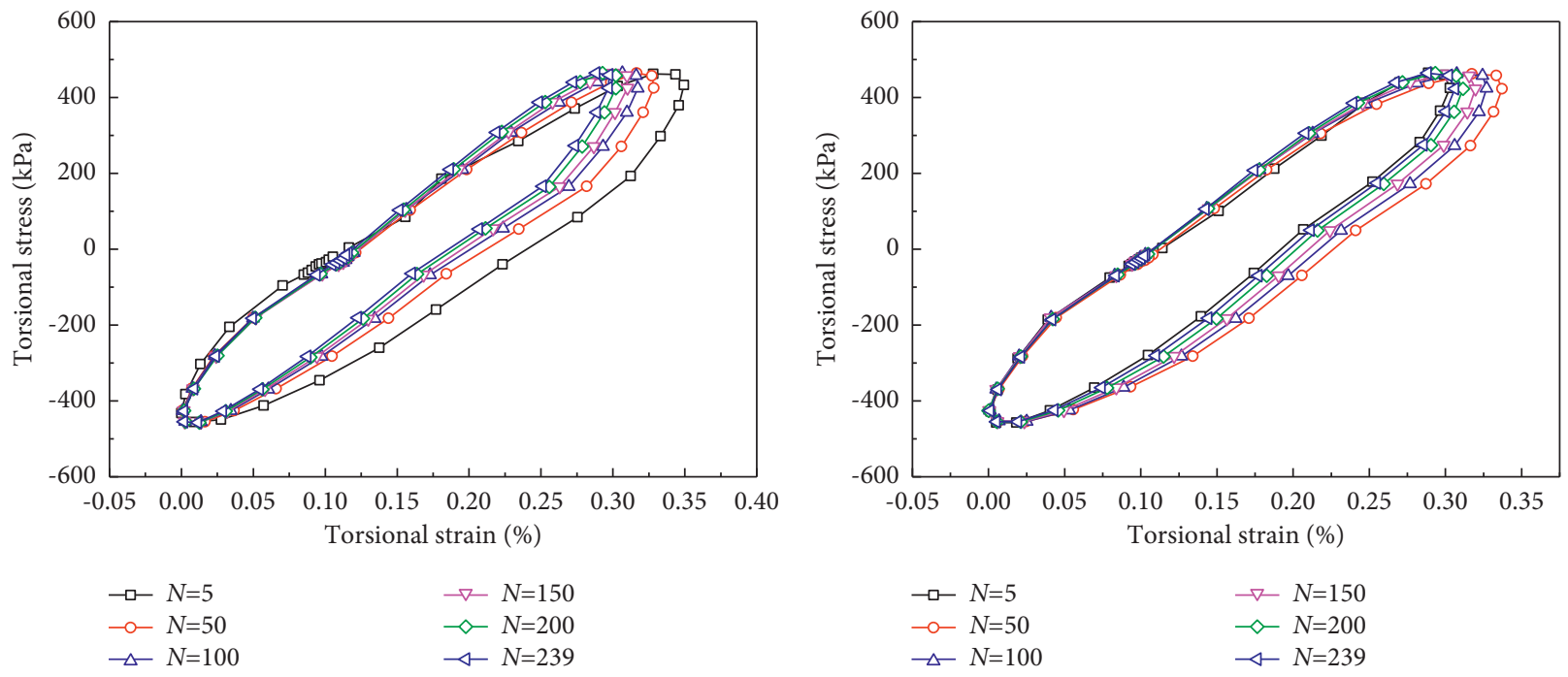

(a)

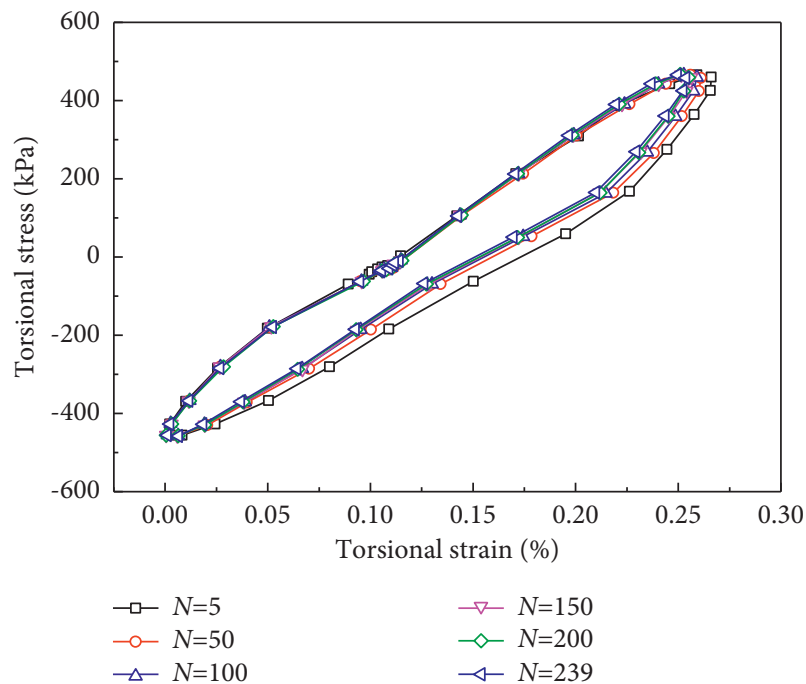

(c)

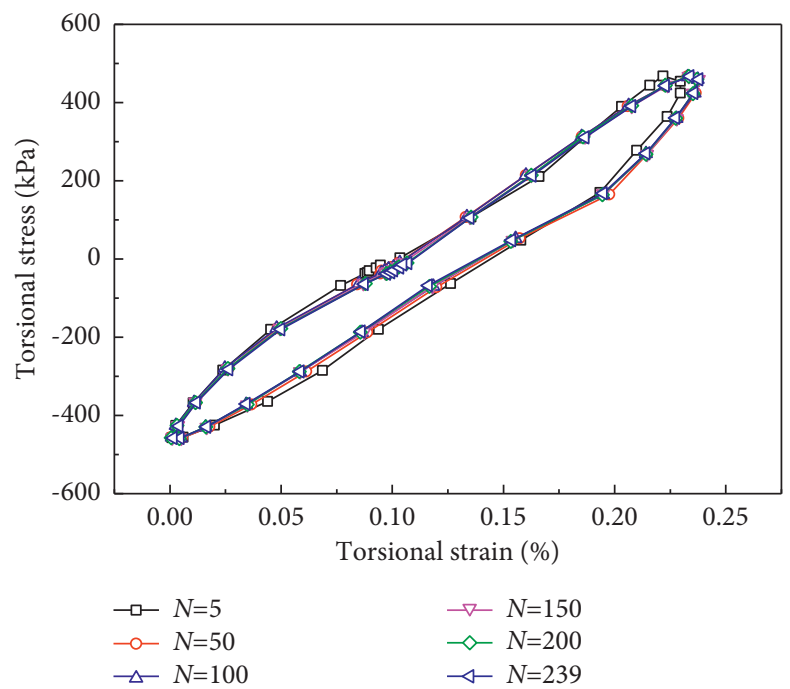

(d)

FiguRE 13: Representative torsional stress-strain responses for a given CSR under different temperatures. (a) $T=-8^{\circ} \mathrm{C}$. (b) $T=-10^{\circ} \mathrm{C}$. (c) $T=-13^{\circ} \mathrm{C}$. (d) $T=-15^{\circ} \mathrm{C}$. 


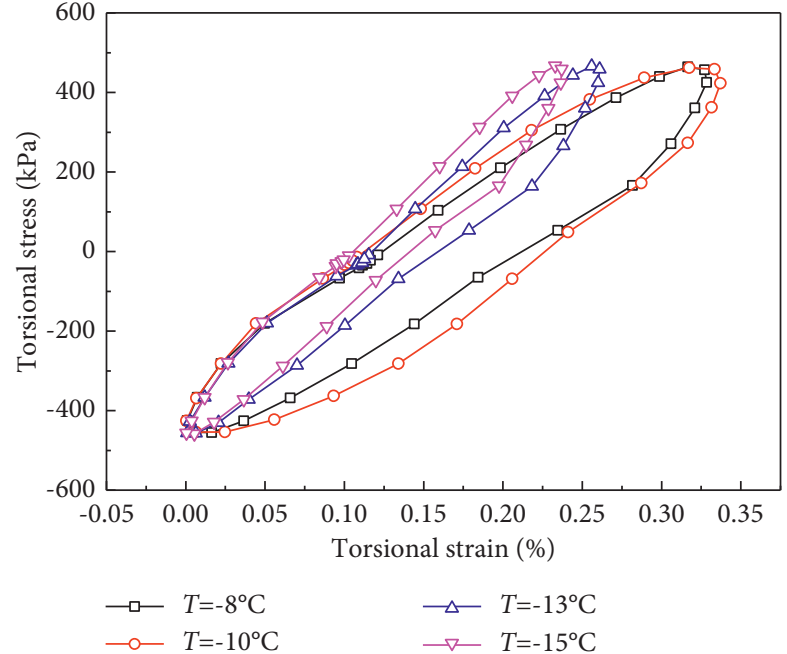

(a)

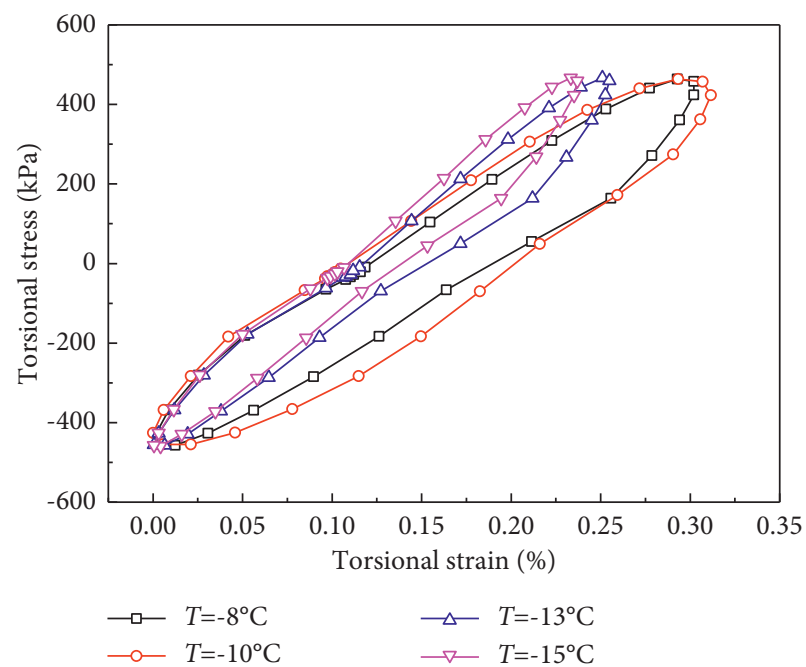

(b)

FiguRE 14: Representative torsional stress-strain responses for a given number of cycles under different temperatures. (a) $N=50$. (b) $N=200$.
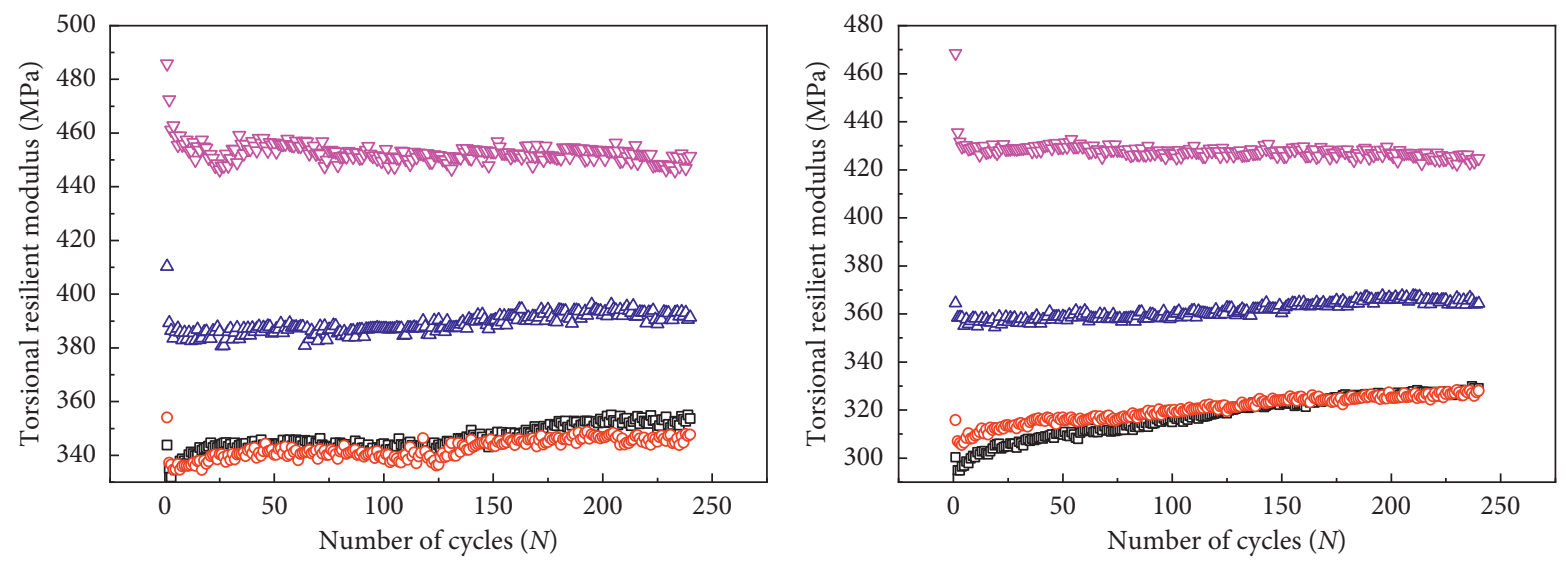
ㅁ $T=-8^{\circ} \mathrm{C}$
- $T=-10^{\circ} \mathrm{C}$
$\triangle T=-13^{\circ} \mathrm{C}$
$\nabla T=-15^{\circ} \mathrm{C}$

ㅁ $T=-8^{\circ} \mathrm{C}$

- $T=-10^{\circ} \mathrm{C}$

$\Delta T=-13^{\circ} \mathrm{C}$

$\nabla \quad T=-15^{\circ} \mathrm{C}$

(a)
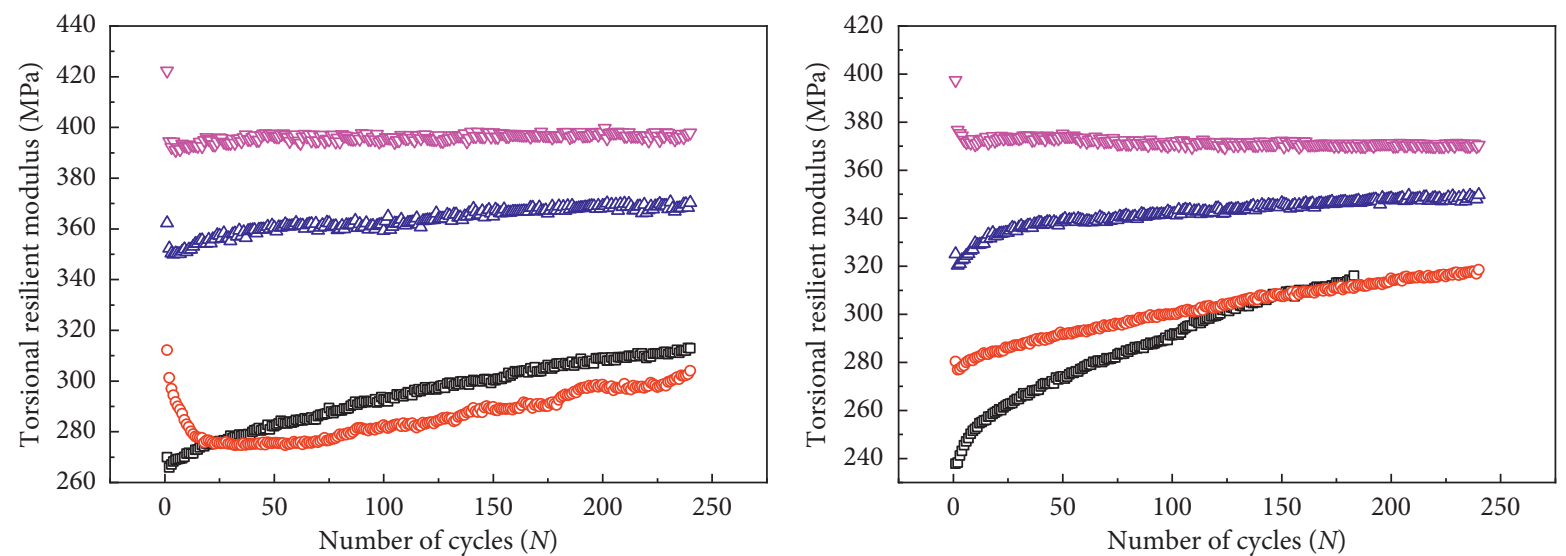
- $\quad T=-8^{\circ} \mathrm{C}$
- $T=-10^{\circ} \mathrm{C}$
$\Delta T=-13^{\circ} \mathrm{C}$
$\nabla \mathrm{T}=-15^{\circ} \mathrm{C}$

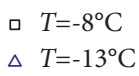

- $T=-10^{\circ} \mathrm{C}$

$\nabla T=-15^{\circ} \mathrm{C}$

(c)

(d)

FIGURE 15: The evolution of the torsional resilient modulus versus the number of cycles at different temperatures and CSRs. (a) CSR $=0.225$. (b) $\mathrm{CSR}=0.300$. (c) $\mathrm{CSR}=0.375$. (d) $\mathrm{CSR}=0.450$. 

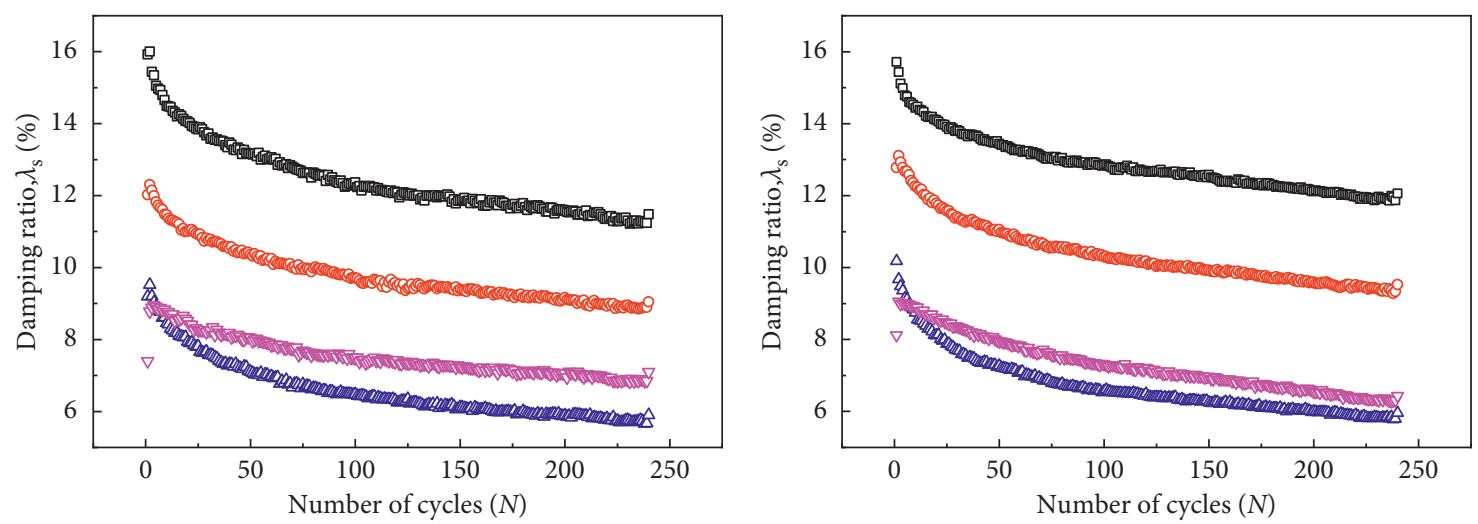
ㅁ $T=-8^{\circ} \mathrm{C}$
$\triangle T=-13^{\circ} \mathrm{C}$
ㅇ $T=-10^{\circ} \mathrm{C}$
$\nabla T=-15^{\circ} \mathrm{C}$

(a)

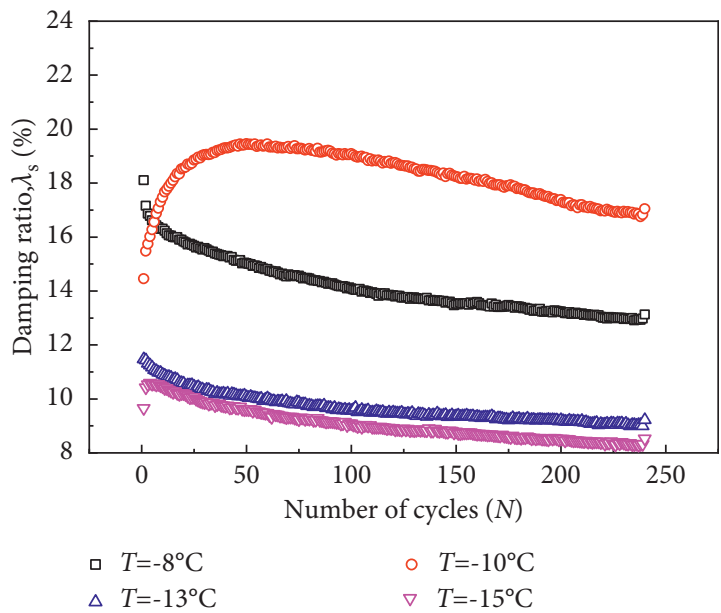

(c)
ㅁ $T=-8^{\circ} \mathrm{C}$
$\triangle T=-13^{\circ} \mathrm{C}$
- $T=-10^{\circ} \mathrm{C}$
$\nabla T=-15^{\circ} \mathrm{C}$

(b)

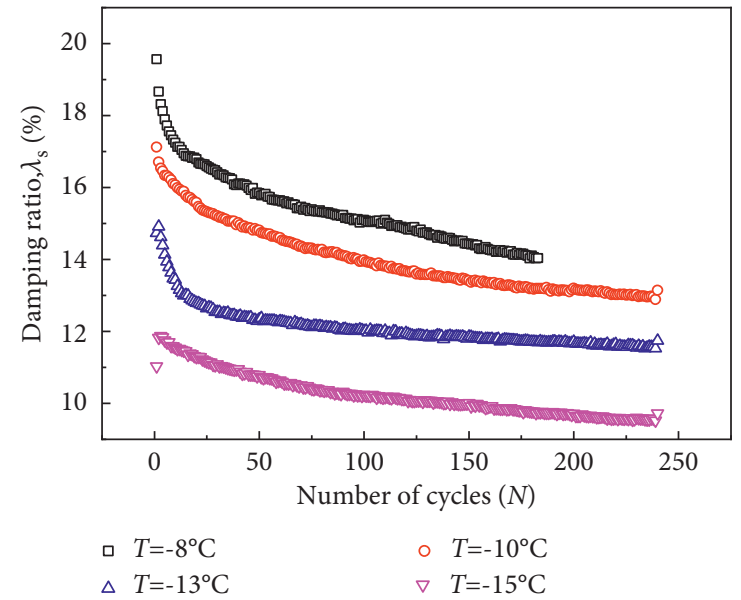

(d)

FIgURE 16: The evolution of the torsional damping ratio versus the number of cycles under different temperatures and CSRs. (a) $\mathrm{CSR}=0.225$. (b) $\mathrm{CSR}=0.300$. (c) $\mathrm{CSR}=0.375$. (d) $\mathrm{CSR}=0.450$.

TABLE 3: Common resilient modulus models.

\begin{tabular}{lc}
\hline Models & Reference \\
\hline$M_{R}=k_{1} \theta^{k_{2}}$ & Zhou et al. [42] \\
$M_{R}=k_{1} \theta^{k_{2}} \sigma_{d}{ }^{k_{3}}$ & You et al. [43] \\
$M_{R}=k_{1} P_{a}\left(\theta / P_{a}\right)^{k_{2}}\left(\tau_{\text {oct }} / P_{a}+1\right)^{k_{3}}$ & Al-Rkaby et al. [44] \\
$M_{R}=k_{1} P_{a}\left(\sigma_{3} / P_{a}+1\right)^{k_{2}}\left(\sigma_{d} / P_{a}+1\right)^{k_{3}}$ & Fu and Dafalias [45] \\
$M_{R \text { (frozen) }}=k_{1}\left(|T| / T_{\text {ref }}\right)^{k_{2}}\left(\sigma_{3} / \sigma_{\text {ref }}\right)^{k_{3}}$ & Zhao et al. [46] \\
\hline
\end{tabular}

noted that the influences of shear stress and bulk stress are regularly considered, and few prediction models are expressed as a function with considering the temperature. Actually, a remarkable finding of this research is that the axial resilient modulus is uniquely related to temperature and CSR. Consequently, the introduction of CSR and temperature in frozen soil axial resilient modulus prediction model is helpful for mechanistic-empirical design of engineering for cold regions or artificial ground freezing projects.

The prediction model proposed by Fu and Dafalias [45] is widely used, as it not only takes $3 \mathrm{D}$ stress state into consideration but also overcomes problems of the undefined resilient modulus values when confining pressure and shear stresses approach 0 . In this study, a prediction model of axial resilient modulus including (Equation (3)) the influences of CSR and temperature is proposed when confining pressure is held constant, based on the modified universal model established by Fu and Dafalias [45].

$$
M_{R}=k_{1} P_{f a}(\mathrm{CSR}+1)^{k_{2}} \times\left(\frac{T}{T_{\text {ref }}}\right)^{k_{3}},
$$

where $k 1, k 2$, and $k 3$ are regression coefficients, CSR is cyclic shear stress ratio, Tref is the reference temperature of $-15^{\circ} \mathrm{C}$, $T$ is experimental temperature, and $P f a$ is the reference pressure of $100 \mathrm{MPa}$.

After that, to obtain the parameter of the modified prediction model, Equation (3) is applied to fit the mean values of axial resilient modulus determined by the mean value of axial resilient modulus in all 240 cycles. Because the experimental data of the average axial resilient modulus at $-10^{\circ} \mathrm{C}$ are relatively scattered, where the data of $-8^{\circ} \mathrm{C},-13^{\circ} \mathrm{C}$, 
TABLE 4: Regression parameters and $R^{2}$ for axial resilient modulus predictive models.

\begin{tabular}{lcccr}
\hline Temperature $/{ }^{\circ} \mathrm{C}$ & $k_{1}$ & $k_{2}$ & $k_{3}$ & $R^{2}$ \\
\hline-8 & 36.084 & -3.244 & 0.401 & 0.986 \\
-13 & 22.472 & -1.294 & 0.401 & 0.754 \\
-15 & 26.859 & -1.778 & 0.401 & 0.974 \\
\hline
\end{tabular}

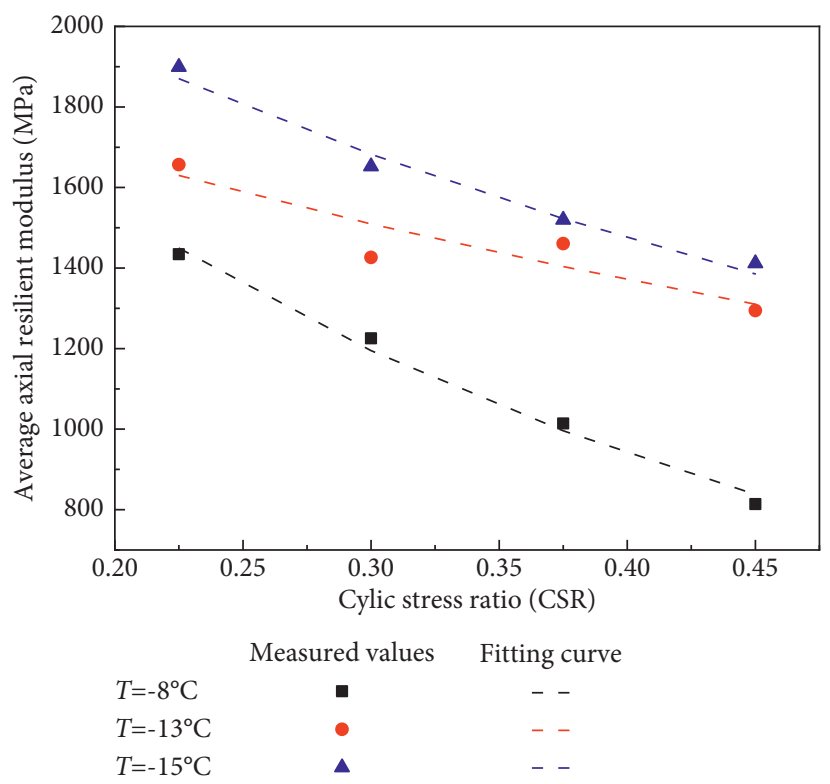

Figure 17: Comparison of optimal fitting curves and measured average axial resilient modulus under different temperature.

and $-15^{\circ} \mathrm{C}$ are used to fit the model parameters, a comparison of optimal fitting curves and measured average axial resilient modulus is shown in Figure 16, and the corresponding regression parameters and $R 2$ for the axial resilient modulus prediction model are listed in Table 4. As shown in Figure 17 and Table 4, the fitting curves of the prediction model are relatively intimate to the measured data, indicating that the proposed model is feasible. However, it should be pointed out that some factors have not be taken in this prediction model, such as the confining pressure and frequency. Additionally, the modified model needs more experimental data to verify.

\section{Conclusions}

In this research, a series of FHCA tests were performed to investigate the effect of temperature on dynamic characteristics of frozen clay under complex stress path involving principal stress rotation. The evolutions of cumulative plastic strain, hysteresis loop, resilient modulus, and damping ratio were analyzed. Based on test results, the following main conclusions can be obtained from this study:

(1) The temperature has a significant influence on the generalized cumulative plastic. The cumulative plastic strain rate is greater with the temperature increase, resulting in greater final cumulative plastic strain. The effect of temperature seems to be more profound with a high CSR.
(2) Axial resilient modulus decreases at the initial stage and then increases with the increased number of cycles under different temperatures. The phenomenon of rearrangement on the particles and cyclic densification is obvious under principal stress rotation. As the number of cycles increases, axial damping ratio gradually decreases at low temperature and small CSR. However, due to the microfracturing phenomenon, the axial damping ratio first decreases and then increases at high temperatures and high CSRs. The high temperature leads to the small axial resilient modulus and large axial damping ratio.

(3) The evolution characteristic of torsional resilient versus the number of cycles mostly depends on temperature. According to the different temperatures, the evolution of torsional resilient modulus can be classified into three categories: the torsional resilient modulus gradually decreases and tends to stabilize, the torsional resilient modulus decreases at the initial cycles and then gradually increases, and the torsional resilient modulus gradually increases and tends to stabilize. The torsional damping ratio decreases with the increase of the number of cycles. The high temperature results in the small torsional resilient modulus and large torsional damping ratio.

(4) Based on the test results, an improved axial resilient modulus prediction model is established with 
considering the influences of cyclic shear stress ratios and temperatures. The new model has been proven to have high fitting accuracy through comparison with the measured values.

The above conclusions provide a better understanding of the long-term dynamic engineering geological characteristics of frozen clay under complex stress path involving principal stress rotation, which could potentially be used for engineering design and contribute to ensuring the service life of frozen soil infrastructures.

\section{Data Availability}

The experimental data used in this research are included within the paper.

\section{Conflicts of Interest}

The authors declare that they have no conflicts of interest or personal relationships that could have appeared to influence the work reported in this paper.

\section{Acknowledgments}

The authors appreciate the help of Zhi-Wei Zhou in revising the paper. The work presented in this paper was supported by the National Natural Science Foundation of China under Grants nos. 41671069 and 41871054 . This financial support is gratefully acknowledged.

\section{References}

[1] O. B. Andersland and B. Ladanyi, Frozen Ground Engineering, American Society of Civil Engineers, Reston, VA, USA, 2004.

[2] G. Nader, B. Li, A. Sohail, and C. Benoît, "Experimental study of rate-dependent uniaxial compressive behaviors of two artificial frozen sandy clay soils," Cold Regions Science and Technology, vol. 180, pp. 1-13, 2020.

[3] L. F. Zheng, Y. T. Gao, Y. Zhou, T. Liu, and S. G. Tian, “A practical method for predicting ground surface deformation induced by the artificial ground freezing method," Computers and Geotechnics, vol. 130, pp. 1-16, 2021.

[4] W. Ma and D. Y. Wang, Mechanics of Frozen Soils, Science Press, Beijing, China, 2014.

[5] X.-Z. Ling, Z.-Y. Zhu, F. Zhang et al., "Dynamic elastic modulus for frozen soil from the embankment on Beiluhe Basin along the Qinghai-Tibet Railway," Cold Regions Science and Technology, vol. 57, no. 1, pp. 7-12, 2009.

[6] X. Z. Ling, F. Zhang, Q. L. Li, L. S. An, and J. H. Wang, "Dynamic shear modulus and damping ratio of frozen compacted sand subjected to freeze-thaw cycle under multistage cyclic loading," Soil Dynamics and Earthquake Engineering, vol. 76, pp. 111-121, 2015.

[7] Z. J. Wu, D. Zhang, T. Zhao, J. J. Ma, and D. Y. Zhao, “An experimental research on damping ratio and dynamic shear modulus ratio of frozen silty clay of the Qinghai-Tibet engineering corrido," Transportation and Geotechnics, vol. 21, pp. 1-9, 2019.

[8] F. T. Zhao, L. J. Chang, and W. Y. Zhang, "Experimental investigation of dynamic shear modulus and damping ratio of Qinghai-Tibet frozen silt under multi-stage cyclic loading," Cold Regions Science and Technology, vol. 170, pp. 1-11, 2020.
[9] T. S. Vinson, T. Chaichanavong, and R. L. Czajkowski, "Behavior of frozen clay under cyclic axial loading," Journal of the Geotechnical Engineering Division, vol. 104, no. 7, pp. 779-800, 1978.

[10] J. C. Li, G. Y. Baladi, and O. B. Andersland, "Cyclic triaxial tests on frozen sand," Engineering Geology, vol. 13, no. 1-4, pp. 233-246, 1979.

[11] G. D. Jiao, S. P. Zhao, and W. Ma, "Experimental study of the dynamic characteristics of warm-frozen silt after freeze-thaw cycles under cyclic loading," China Civil Engineering Journal, vol. 43, pp. 107-113, 2010, in Chinese.

[12] L. N. Wang, X. Z. Ling, Q. L. Li, J. Wang, and Y. H. Liu, "Accumulative plastic strain of frozen silt clay under cyclic loading," Applied Mechanics and Materials, vol. 501-504, pp. 38-42, 2014.

[13] E. Liu, Y. Lai, M. Liao, X. Liu, and F. Hou, "Fatigue and damage properties of frozen silty sand samples subjected to cyclic triaxial loading," Canadian Geotechnical Journal, vol. 53, no. 12, pp. 1939-1951, 2016.

[14] X. Ling, Q. Li, L. Wang, F. Zhang, L. An, and P. Xu, "Stiffness and damping radio evolution of frozen clays under long-term low-level repeated cyclic loading: experimental evidence and evolution model," Cold Regions Science and Technology, vol. 86, pp. 45-54, 2013.

[15] Q. Li, X. Z. Ling, J. J. Hu, and X. T. Xu, "Experimental investigation on dilatancy behavior of frozen silty clay subjected to long-term cyclic loading," Cold Regions Science and Technology, vol. 153, pp. 156-163, 2018.

[16] Q. L. Li, X. Z. Ling, J. J. Hu, and Z. W. Zhou, "Residual deformation and stiffness changes of frozen soils subjected to high and low amplitude cyclic loading," Canadian Geotechnical Journal, vol. 56, no. 2, pp. 263-274, 2018.

[17] D. Zhang, Q. Li, E. Liu, X. Liu, G. Zhang, and B. Song, "Dynamic properties of frozen silty soils with different coarsegrained contents subjected to cyclic triaxial loading," Cold Regions Science and Technology, vol. 157, pp. 64-85, 2019.

[18] X. Xu, Q. Li, and G. Xu, "Investigation on the behavior of frozen silty clay subjected to monotonic and cyclic triaxial loading," Acta Geotechnica, vol. 15, no. 5, pp. 1289-1302, 2020.

[19] Z. W. Zhou, W. Ma, G. Y. Li, and M. D. Shen, "A novel evaluation method for accumulative plastic deformation of granular materials subjected to cyclic loading: taking frozen subgrade soil as an example," Cold Regions Science and Technology, vol. 179, pp. 1-13, 2020.

[20] J. R. F. Arthur, J. I. Rodriguez del C, T. Dunstan, and K. S. Chua, "Principal stress rotation: a missing parameter," Journal of the Geotechnical Engineering Division, vol. 106, no. 4, pp. 419-433, 1980.

[21] A. Mandolini, A. Diambra, and E. Ibraim, "Stiffness of granular soils under long-term multiaxial cyclic loading," Géotechnique, vol. 19, pp. 1-43, 2020.

[22] Y. H. Zhao, Y. M. Lai, J. Zhang, and R. Q. Bai, "A bounding surface model for frozen sulfate saline silty clay considering rotation of principal stress axes," International Journal of Mechanical Sciences, vol. 177, pp. 1-38, 2020.

[23] Y. Nakata, M. Hyodo, H. Murata, and N. Yasufuku, "Flow deformation of sands subjected to principal stress rotation," Soils and Foundations, vol. 38, no. 2, pp. 115-128, 1998.

[24] Z.-X. Tong, J.-M. Zhang, Y.-L. Yu, and G. Zhang, "Drained deformation behavior of anisotropic sands during cyclic rotation of principal stress axes," Journal of Geotechnical and Geoenvironmental Engineering, vol. 136, no. 11, pp. 15091518, 2010. 
[25] A. Erken and B. M. C. Ulker, "Effect of cyclic loading on monotonic shear strength of fine-grained soils," Engineering Geology, vol. 89, no. 3-4, pp. 243-257, 2006.

[26] B. Huang, X. Chen, and Y. Zhao, "A new index for evaluating liquefaction resistance of soil under combined cyclic shear stresses," Engineering Geology, vol. 199, pp. 125-139, 2015.

[27] A. Mamou, J. A. Priest, C. R. I. Clayton, and W. Powrie, "Behaviour of saturated railway track foundation materials during undrained cyclic loading," Canadian Geotechnical Journal, vol. 55, no. 5, pp. 689-697, 2018.

[28] Y. K. Wang, M. S. Han, X. Yu, Y. S. Wan, J. G. Shao, and D. B. Ren, "Stiffness degradation of natural soft foundation in embankment dam under complex stress paths with considering different initial states," Applied Ocean Research, vol. 104, pp. 1-22, 2020.

[29] Y. Cai, Q. Sun, L. Guo, C. H. Juang, and J. Wang, "Permanent deformation characteristics of saturated sand under cyclic loading," Canadian Geotechnical Journal, vol. 52, no. 6, pp. 795-807, 2015.

[30] J.-G. Qian, Z.-B. Du, and Z.-Y. Yin, "Cyclic degradation and non-coaxiality of soft clay subjected to pure rotation of principal stress directions," Acta Geotechnica, vol. 13, no. 4, pp. 943-959, 2018.

[31] S. Wang, Z. Zhong, X. Liu, and Y. Tu, "Influences of principal stress rotation on the deformation of saturated loess under traffic loading," KSCE Journal of Civil Engineering, vol. 23, no. 5, pp. 2036-2048, 2019.

[32] Q. Sun, Q. Dong, Y. Cai, J. Wang, and X. Song, "Drained deformation characteristics of granular soil under pure principal stress axis rotation: impact of sample preparation," Acta Geotechnica, vol. 16, no. 6, pp. 1755-1772, 2021.

[33] Y. Guo, D. Y. Wang, W. Ma, and Y. H. Mu, "Development and application of frozen hollow cylinder apparatus," Journal of Harbin Institute of Technology, vol. 48, no. 12, pp. 114-120, 2016, in Chinese.

[34] L. L. Lei, D. Y. Wang, Y. T. Wang, D. Chen, and W. Ma, "The strength characteristics of frozen clay under the different principal stress directions," Journal of Harbin Institute of Technology, vol. 50, no. 6, pp. 103-109, 2018, in Chinese.

[35] K. Ishihara and I. Towhata, "Sand response to cyclic rotation of principal stress directions as induced by wave loads," Soils and Foundations, vol. 23, no. 4, pp. 11-26, 1983.

[36] H. B. Seed and I. M. Idriss, "Simplified procedure for evaluating soil liquefaction potential," Journal of the Soil Mechanics and Foundations Division, vol. 97, no. 9, pp. 1249-1273, 1971.

[37] F. Amini and A. Chakravrty, "Liquefaction testing of layered sand-gravel composites," Geotechnical Testing Journal, vol. 27, no. 1, pp. 36-46, 2004.

[38] K. O. Cetin, B. Unutmaz, and B. Jeremic, "Assessment of seismic soil liquefaction triggering beneath building foundation systems," Soil Dynamics and Earthquake Engineering, vol. 43, pp. 160-173, 2012.

[39] D. Chen, D. Wang, W. Ma, L. Lei, and G. Li, "A strength criterion for frozen clay considering the influence of stress Lode angle," Canadian Geotechnical Journal, vol. 56, no. 11, pp. 1557-1572, 2019.

[40] Z. Zhou, W. Ma, S. Zhang, Y. Mu, S. Zhao, and G. Li, "Yield surface evolution for columnar ice," Results in Physics, vol. 6, pp. 851-859, 2016.

[41] Z. Zhou, W. Ma, S. Zhang, C. Cai, Y. Mu, and G. Li, "Damage evolution and recrystallization enhancement of frozen loess," International Journal of Damage Mechanics, vol. 27, no. 8, pp. 1131-1155, 2018.
[42] Z. Zhou, W. Ma, S. Zhang, Y. Mu, and G. Li, "Experimental investigation of the path-dependent strength and deformation behaviours of frozen loess," Engineering Geology, vol. 265, Article ID 105449, 2020.

[43] Z. L. You, Y. W. Ma, Z. Y. Wang, and J. Ma, “Tensile strength variation of asilty clay under different temperature and moisture conditions," Cold Regions Science andTechnology, vol. 189, pp. 1-9, 2021.

[44] A. H. J. Al-Rkaby, A. Chegenizadeh, and H. R. Nikraz, "Cyclic behavior of reinforced sand under principal stress rotation," Journal of Rock Mechanics and Geotechnical Engineering, vol. 9, no. 4, pp. 585-598, 2017.

[45] P. Fu and Y. F. Dafalias, "Fabric evolution within shear bands of granular materials and its relation to critical state theory," International Journal for Numerical and Analytical Methods in Geomechanics, vol. 35, no. 18, pp. 1918-1948, 2011.

[46] F. T. Zhao, L. J. Chang, and W. Y. Zhang, "Analysis on the influence of cyclic stress ratio and vibration frequency on microstructure of saline soil," Journal of Glaciology and Geocryology, vol. 42, no. 3, pp. 854-864, 2020, in Chinese. 